Max-Planck-Institut für demografische Forschung

Max Planck Institute for Demographic Research

Konrad-Zuse-Strasse 1 - D-18057 Rostock - GERMANY

Tel +49 (0) 3812081 - 0; Fax +49 (0) 3812081 - 202;

http://www.demogr.mpg.de

MPIDR WORKING PAPER WP 2003-017

JUNE 2003

Completing Education and

the Timing of Births and Marriage:

Findings from a

Birth-Month Experiment in Sweden

Vegard Skirbekk (skirbekk@demogr.mpg.de)

Hans-Peter Kohler (hpkohler@pop.upenn.edu)

Alexia Prskawetz (fuernkranz@ demogr.mpg.de)

(C) Copyright is held by the authors.

Working papers of the Max Planck Institute for Demographic Research receive only limited review.

Views or opinions expressed in working papers are attributable to the authors and do not necessarily reflect those of the Institute. 


\title{
Completing Education and the Timing of Births and Marriage: Findings from a Birth-Month Experiment in Sweden
}

\author{
Vegard Skirbekk, Hans-Peter Kohler and Alexia Prskawetz ${ }^{*}$
}

\begin{abstract}
:
We investigate the timing of fertility and marriage as it depends on educational attainment utilizing a birthmonth experiment in Sweden that leads to exogenous variation in the age at completing schooling. Our analysis finds that the difference of 11 months in the age at school-leaving between women born in two consecutive months, December and January the following year, implies a delay in the age at first birth of 4.9 months. This effect of delayed graduation also persists for second births and the age at first marriage, but it does not affect completed fertility or the overall probability to marry prior to age 45 .
\end{abstract}

\footnotetext{
* Skirbekk is Ph.D. student at the Max Planck Institute for Demographic Research, Konrad-Zuse-Straße 1, 18057 Rostock, Germany; Email: skirbekk@demogr.mpg.de. Prskawetz is Head of Research Group on Population, Economy, and Environment at the Max Planck Institute for Demographic Research, KonradZuse-Straße 1, 18057 Rostock, Germany; Email: Fuernkranz@ demogr.mpg.de . Kohler is Associate Professor of Sociology, 3718 Locust Walk, University of Pennsylvania, Philadelphia, PA 19104-6299, USA; Email: hpkohler@ pop.upenn.edu, homepage: http://www.ssc.upenn.edu/ hpkohler. The authors would like to thank Gunnar Andersson, Jan Hoem, Birgitta Lidholt, Ingrid Lindskog, Jonathan MacGill and Michaela Kreyenfeld for valuable help in writing this paper, and they gratefully acknowledge the Max Planck Institute for Demographic Research for supporting this project.
} 


\section{Introduction}

The timing of childbearing is an increasingly important aspect of fertility patterns in low fertility contexts. In Sweden, for instance, the mean age at first birth has increased in the last 25 years from 24.4 (1975) to 27.9 (2000), and this trend has been shared with many other European and developed countries (Council of Europe 2001). Moreover, delay of childbearing has also been associated with substantial declines in the level of fertility. For instance, in Sweden the baby boom during the 1980s, which resulted in an increase of the total fertility from a level of 1.61 (1983) to a peak of 2.14 (1990), coincided with a reduced pace in the trend towards delayed childbearing, while the postponement of fertility regained its earlier strength after 1990 as the total fertility rate declined and reached a trough in 1998 of 1.51 (Statistics Sweden 2002). This association between the delay of childbearing and fertility has even been more pronounced in countries that have experienced declines to unprecedented low levels of fertility during the 1990s. For instance, between 1980 and 1997 the mean age at first birth in Italy has risen from 25.0 to 28.7 years, and the total fertility rate (TFR) has declined from 1.64 to 1.20; in Spain the mean age at first birth has increased from 25.0 to 29.0 years during 1980 to 1999, while the TFR declined from 2.20 to 1.20 (Council of Europe 2001). Similar developments have also occurred in many Central and Eastern European countries during the 1990s. Kohler et al. (2002) have argued in their analyses of these declines of the total fertility rate below 1.3 - or to lowest-low fertility levels - that the postponement of fertility in connection with these TFR declines is due to two factors: first, socio-economic incentives such as increased returns to education or high level of youth unemployment that make late childbearing a rational decision for couples or individuals, and second, social interaction effects that reinforce the trends towards delayed childbearing through social learning, social influence and other feedback effects that affect the timing of fertility. In addition, Kohler et al. argue that the delay of childbearing had important causal effects towards reducing the level of fertility, which is consistent with several other studies that have also documented a negative relation between the age at first birth and the level of completed fertility (Bumpass et al. 1978; Marini and Hodson 1981; Morgan and Rindfuss 1991; Trussel and Menken 1978).

Most analyses of the timing of fertility_including those in Kohler et al. (2002)—emphasize the role of human capital investments in early adulthood, and in particular the substantial increases in female's investments in higher or professional education, in response to increased returns to human capital, improved access to the labour market and more effective contraception (see for instance Gustafsson 2001; Goldin and Katz 2002; Westoff and Ryder 1977). Goldin and Katz (2002), for instance, argue that the introduction of the pill has enabled women to enjoy sexual relations without jeopardizing time-consuming and expensive investments in human capital investments through an unwanted birth, and the study argues that ability to control fertility has been an important factor in the increased enrolment of women in university education and the increased proportion of women in "career-sectors" of the labour market. Similarly, Blossfeld and Huinink (1991) have shown that few women have children during education-a 
pattern that is consistent with the argument by Goldin and Katz-and that the hazard of experiencing a birth increases substantially after education is completed.

Despite this emphasis on the role of education and human capital investments, very few studies have succeeded in establishing the causal effects of "years in education" or "age at graduation" on fertility patterns. In particular, analyses of this question are hampered by the fact that many unobserved characteristics that affect marriage and fertility are likely to affect also the opportunities or incentives to invest in human capital. Standard analyses of the relation between education and fertility are therefore likely to be distorted. Analyses that can overcome this problem need to rely on instrumental variable techniques, fixed effect models or "natural experiments" (Rosenzweig and Wolpin 2000). In this study we pursue the last approach, natural experiments, and utilize the fact that children in Sweden are enrolled in school in the calendar year in which they become seven years old. Children who are born during two consecutive months, December and January, therefore graduate in two different calendar years. Hence, they differ by almost one year in the age at graduation from compulsory schooling, despite the fact that they are born merely one month apart on average. Under the assumption that parents cannot time the births of their children very accurately to the exact month, this characteristic of the Swedish school system results in an exogenous variation in the age at completing compulsory education (and also in the age at graduating from higher levels of education among those who continue after compulsory schooling).

In this study we utilize this "natural experiment" provided by Swedish school-enrolment laws in order to investigate whether a different age at graduation from school, which is induced by differences in women's month of birth, leads to systematic and relevant differences in the marriage and fertility pattern of Swedish women born during 1946 to 1962 . Our study finds that small differences in the age of exiting school have relatively profound effects on the timing of fertility and marriage, while they do not seem to affect the level of completed fertility and the probability to marry prior to age 45 . An eleven month difference in the age at graduation between those born in December and the subsequent January, for instance, results in an almost five months difference in the timing of first births; or equivalently, more than $40 \%$ of the difference in the age at graduation from compulsory schooling are not compensated during the 8-10 years in early adulthood that are on average between graduation from primary school and the birth of the first child. Moreover, our study finds that the timing between the first and the second child changes remarkably little in response to the changes in the age at first birth caused by different years of graduation of December- and January-born women, indicating the absence of a conscious compensation for birth-month induced variation in the age at first birth. Our study also finds similar birth-month effects within birth-cohorts, where January-born women tend to experience births and marriage at an older age than women born in December. In summary, these findings suggest that important timing aspects of fertility are much less related to specific age patterns, but instead, to the time since completing primary school. 


\section{Survey of Theory and Research Findings on education and fertility}

Women usually wait with children until after they have finished their educational careers (e.g. Blossfeld and Huinink 1991; see also Statistics Sweden 1998). This strong effect of enrolment in education on the timing of fertility is caused by several factors (Becker 1991; Schultz 1993; Oppenheimer 1988), including (a) the incompatibility of education and childrearing, (b) the increased risk of not completing education due to a birth and the high opportunity costs of failing to complete education, (c) the high life-cycle costs of delaying completing education and delaying the entrance into the labour market, especially in developed countries with high returns to human capital, (d) the desire to "establish" oneself in the career after completing education and before having a child, and (e) social norms that discourage childbearing while women (or couples) are still in education. This effect of educational enrolment toward delaying childbirth has also been reinforced because the increase in the length of education occurred at the same time as other fundamental cultural and societal changes took place during the Second Demographic Transition that have resulted in a different status for women, a shift from traditional to individualistic values, and an increased focus on self-realization (van de Kaa 1987; Lesthaege 1998; Lesthaege and Meekers 1986).

The above incentives and norms have led to a very typical sequencing of demographic events in early adulthood in which the completion of education precedes the first birth (Blossfeld and De Rose 1992; Corijn 1996; Marini 1984). This sequencing pattern also prevails in Sweden-that is, the country of our investigations - despite the fact that generous benefits during childbearing have reduced the costs of children in general. At the same time, the Swedish child benefits also include an explicit incentive to enter the labour market and materialize the high returns to learning on the job and job experience early in the career. In particular, the benefits paid to women for up to 480 days after the birth of a child relates in part to the female labour income prior to childbirth (Riksförsakringsverket 2002). Entering the labour market and gaining experience on the job prior to the birth of a child, therefore, implies higher benefits during maternity leave and this aspect may provide an important disincentive for childbearing during education.

Despite this important role of education for the changes in the timing of fertility in recent decades, many of the studies that address this issue have been hampered by methodological challenges pertaining to sample selectivity and unobserved heterogeneity. In particular, studies of the relation between completing education and the timing of fertility are usually based on comparisons of subgroups of women with different educational degrees. However, a common problem in these studies is that women who differ in their educational attainment also differ with respect to other unobserved characteristics that not only affect educational attainment but also the fertility and marriage. For instance, these unobserved characteristics such as preferences, abilities, family backgrounds, etc., are likely to affect the educational attainment as well as the timing of fertility conditional on education, and this effect biases standard analyses of the relation between education and the timing of fertility.

One attempt to overcome the problems induced by selectivity in abilities and preferences is a study by Kohler et al. (2001) of the-commonly negative_relation between the age at first birth and completed 
fertility. By comparing monozygotic twins with different educational attainment, the study compares individuals with identical biological endowments, identical parental households and similar socialization experiences. Using within-MZ pair estimates therefore provides a possibility to control for important sources of heterogeneity, including genetic endowments and parental influences. Nevertheless, even these within-MZ estimates remain potentially affected by unobserved individual-specific shocks that are correlated with both an individual's educational attainment and fertility behavior. For instance, matching in the marriage market, partner characteristics and related aspects of household bargaining may systematically differ even between MZ twins and these aspects continue to be problematic even in within MZ pairs estimation. Several other econometric approaches have also been used to overcome the endogeneity problems associated with education in analyses of fertility behavior (Neiss et al. 2002 and Retherford and Sewell 1989), but often the studies need to rely on strong assumptions in order to identify "causal influences" of education on the timing and level of fertility. The presence of these factors renders standard analyses of the relation between fertility and education biased. ${ }^{1}$

In summary, because education and fertility behavior are likely to be correlated with similar observed and unobserved individual characteristics, the causal relation between education and fertility behavior has proven to be difficult to disentangle. In particular, the estimation of causal education effects requires either exogenous shocks in the level of education or instrumental variables that can predict variation in educational attainment without being correlated with relevant unobserved individual characteristics. A recent literature in economics has started to emphasize the use of "natural experiments" that generate exogenous variation in right-hand-side variables included in regression equations, and this approach can overcome endogeneity problems such as with respect to education and fertility. In this paper we follow this literature and propose a particularly simple and intuitive "experiment" that allows us to identify the causal marginal effect of the age at finishing primary education on the timing of first childbirth. In particular, we use the fact that children in Sweden are enrolled in elementary school in the calendar year in which they turn seven years old. In combination with relatively fixed duration of compulsory education up to $9^{\text {th }}$ grade,

\footnotetext{
${ }^{1}$ This bias can be specified in the simple regression model for the relation of fertility, denoted $y_{i}$, on years of education, denoted $x_{i}$. The regression then specifies $y_{i}=b_{0}+b_{1} x_{i}+u_{i}+e_{i}$, where $b_{1}$ is the coefficient of interest, and $u_{i}$ and $e_{i}$ represent unobserved characteristics. Endogeneity problems due to unobserved characteristics for instance arise if $x_{i}$ is determined as $x_{i}=a_{0}+a_{1} z_{i}+a_{2} u_{i}+v_{i}$ where $z_{i}$ are observed determinants of education, such as parental characteristics, and $v_{i}$ represents unobserved influences. Even if $e_{i}$ is independent of $v_{i}$, the presence of $u_{i}$ in the relation for $x_{i}$ implies that the education variable $x_{i}$ is correlated with the unobserved term in the regression equation for $y_{i}$. In this case, OLS does not provide unbiased or consistent estimates for the coefficient $b_{l}$. Instead, the regression yields
} $\operatorname{plim} \tilde{\mathrm{b}}_{1}=\mathrm{b}_{1}+\mathrm{a}_{2} \frac{\operatorname{var}\left(\mathrm{u}_{\mathrm{i}}\right)}{\operatorname{var}\left(\mathrm{x}_{\mathrm{i}}\right)}$, which differs from the true value $b_{1}$ whenever $\operatorname{var}\left(u_{i}\right)>0$ and $a_{2}>0$. 
this results in exogenous variation in the age at completing primary school education depending on the birth month.

\section{Birth month and school enrolment as a natural experiment}

Several studies have documented birth month effects on phenomena such as the risk of suffering from schizophrenia, the sex ratio at birth, and life expectancy (Sham et al. 1992; Nonaka et al. 1987; Doblhammer and Vaupel 2001). The use of birth month in econometric studies of causal influences in behavioral relations is relatively new. In particular, Angrist and Krueger (1991) have pioneered this approach in their investigation of the relation between earnings, educational attainment and school regulations. Also in the US the year of school enrolment in school depends on the birth month of a child. ${ }^{2}$ In addition, the US regulations stipulated a minimum age at graduation that differs over time and across US states and these laws provided a lower age limit at which it was legal to terminate high school education. The Angrist and Krueger study on earnings and schooling of American men born 1920-49, on the basis of US Census data, shows that men born in the first quarter of the year earn less than those born in the three other quarters. The authors try to attribute this small, but significant, finding to compulsory schooling laws, which allows one to exit school only after the age of 16 . The effect of these schooling laws is that those born later in the year receive more education than those born earlier in the year. The ones born in the first quarter of the year will have received less schooling by the time they turn 16 , since the cut off date is late in the year.

The study by Angrist and Krueger stimulated several follow up investigations that have been critical to their conclusions. Bound and Jaeger (1996), for instance, provide evidence that the link between season of birth and educational/labour market success can at least partially be explained by other factors than schooling laws. Studying American white male citizens born 1840-75, a period long before compulsory schooling laws came in effect, they find men born during the summer had a higher income than those born in the winter season. They also show that the relation between education and birth quarter has decreased gradually for those born from 1920 to 1940 in the US, but that the relation between private income and birth quarter was strengthened in the same period, implying that the birth quarter effect is caused by an unobserved factor, rather than compulsory schooling laws.

The Swedish school enrolment differs from the US enrolment rules, and this difference makes Sweden more suitable for using the month of birth as a natural experiment than the United States. A normal Swedish school year starts at the end of August and lasts until the beginning of June the next year. The school year consists of about 40 weeks, and in every week, the children are taught from Monday to Friday. Primary school starts for almost all children the year they turn 7. Primary school lasts for nine years and is finished in June the calendar year the pupils turn 16 (or $n+9$ if they started at the age of $n$ ). Upon

\footnotetext{
${ }^{2}$ Cut off birth dates in the US differ across states from September $1^{\text {st }}$ to January $1^{\text {st}}$; see Angrist and Krueger (1992) for further discussions.
} 
completing primary school, the pupils can choose whether they would like to go on to a vocational or academic program in secondary school (Gymnasieskolan), which normally lasts three years. After graduating from secondary school, roughly one third of the female students eventually continue with tertiary education, while the remaining two thirds do not (e.g. enter the labour market, start a family or sometimes start attending another secondary school track education).

In summary, the Swedish system is characterized by compulsory attendance laws that require the completion of the 9-year education. Since nearly all children ${ }^{3}$ enter school the year they turn 7 , they graduate from primary school when they are 15.5 to 16.5 years old. Graduation at younger ages is impossible (except for the few cases of early enrolment), and graduation at older ages is rare since few students repeat classes and/or enter school at a later age. The most important aspects of this system of enrolment and compulsory completion of $9^{\text {th }}$ grade education is that variation in the month of birth causes a systematic variation in the age at graduation from primary school $\left(9^{\text {th }}\right.$ grade). This effect is most pronounced between children who are born in December and the subsequent January: in each grade, and in particular at completion of the compulsory 9-year education, children born in January will be 11 months older than children born in the preceding December. Less pronounced is the effect of birth month within birth cohorts, where women born in January are 11 months older at completion of high school than women born in December of the same calendar year, and this difference decreases gradually by birth month for women born within the same calendar year.

The differential age in graduation that is caused by the Swedish enrolment system is particularly useful for identifying the effect of educational enrolment on fertility pattern because children born during the consecutive months December--January, and similarly children born within the same calendar year, live their childhood and early adulthood during virtually the same time period. Any period influences on education or fertility, such as changes in the returns to education, economic up- or downswings, or changes in family policy, affect these children identically. Moreover, at graduation, women born in December and January differ in their age, but not in the level of human capital: in both cases, the women have completed $9^{\text {th }}$ grade education and face decisions about the further options within the educational system or entering vocational training. Since many women extend schooling beyond $9^{\text {th }}$ grade and there is no possibility to

\footnotetext{
${ }^{3}$ Almost all children enter school when they turn 7, though some individuals pre- or postpone school entrance. This is usually the case when children start school at the age of six or delay school entrance to the year they turn eight. The proportion of all female pupils who entered school at the age of six, constitutes 1.6-2\% of all six year old females in 1960, 1963, 1966 and 1969, which are the years where there are data available (Statistisk Tidsskrift 1962 and Statistiska Meddelanden 1964, 1968, 1970). The percentage who first started going to school at the age of eight, is not explicitly given. However, from the fact that the population share of the 8 year olds in school is only up to 2.4 percentage points higher than that of 7 year olds we may deduce that very few postponed school entrance. The birth month of the individuals who anticipated or postponed school entrance is unknown.
} 
"catch-up" within the school system, the difference in the age at graduation also propagates to the age at graduation from Gymnasieskolan $\left(12^{\text {th }}\right.$ grade $)$ and potentially also to the age at graduation from university among women who continue education. For women who pursue higher education, therefore, the month of birth is likely to have an effect on the age at graduation substantially beyond the $9^{\text {th }}$ grade. ${ }^{4}$

Based on the above variation in enrolment and age at graduation, our study is able to formulate a simple hypothesis to identify the effect of school enrolment on subsequent fertility outcomes: if the age at graduation from school has an effect on demographic behavior in early adulthood, the timing of demographic events and related demographic behaviours should differ according to birth month. This effect should be most pronounced between individuals born in December and the subsequent January, where our analyses reveal the impact on demographic behavior of graduating at an age of 11 months older. At the same time, a gradual decrease of the age at graduation occurs within each birth cohort. As a consequence, for example, women born in February graduate one month younger than women born in January, and within-cohort comparisons of the fertility and marriage timing reveal the impact of these gradual changes in the age at graduation across birth month.

\section{Recent trends in fertility and educational attainment in Sweden}

Figure 1 shows the trend in Swedish fertility (TFR all parities) and the mean age at first birth from 1975 to 2000. Similar as in many other European countries fertility started declined and stabilized in the 1970s and stabilized by the end of this decade. Whereas fertility levels continued to stagnate or decline in many European countries during the 1980s, Sweden experienced a baby boom after 1985. Between 1985 and 1990 the TFR increased from 1.74 to a level of 2.13, exceeding replacement level. This substantial increase in fertility was caused by an increased propensity for childbearing at very short birth intervals due to the introduction of the so called "speed premium" on childbearing that provided financial incentives to space children closely (Andersson 2002). ${ }^{5}$ The sharp economic down-turn in the early 1990s led to an equally

\footnotetext{
${ }^{4}$ This design of the Swedish school system also avoids some weaknesses of the Angrist and Krueger approach because the identification of educational effects in their studies is due to the possibility of dropping out of school at a lower grade-level for children who are older when they are enrolled in school. Since the majority of students, regardless of birth quarter, do not drop out of school at the youngest age allowed, the compulsory schooling laws are irrelevant to their educational attainment and wages. Our study avoids this problem because we focus on the age at graduation instead which applies to the whole population (Sweden), rather than compulsory school attendance laws that regulate the minimum age of graduation for a minority that drop out of school (United States).

${ }^{5}$ The speed premium refers to rules that were introduced in the Swedish parental-leave system and that allows parents (typically woman) to keep an earlier (and often higher) level of income compensation during
} 
swift baby bust in the 1990s (Andersson 2000; Hoem 2000), and by 1999 the total fertility rate had declined to a historically low level of 1.5. In 2000, a slight recovery of the TFR to 1.54 took place. This change in fertility levels over time has been accompanied by a rapid postponement of fertility. The (period) mean age of first birth, for instance, increased from 24 to 28 years within the three decades from 1970 to 2000 . The only slowdown during this fertility postponement occurred during the period of the baby boom, while the baby bust after 1990 coincides with a renewed increase in the pace of fertility postponement.

Figure 2 shows that the average years of school for females over age 25 has also increased from about 8 years in 1975 to about 11 years by 2000, that is, by almost the same amount as the mean age at first birth (see also Barro and Lee 2000). While compulsory schooling in Sweden ends at the age 16, most women and men stay in upper secondary school for another three years (Stanfors 2003:75ff). For instance, 97.1 per cent of boys and 97.3 per cent of girls in 1998 entered secondary school after completing compulsory schooling. A similar increase in schooling level has occurred across cohorts, and the main difference is that the extension of schooling has been even more pronounced among women than men (Table 1). For instance, about a third of all women in the 1929 cohort participated in secondary education, while only 10 per cent participated in higher education; these enrollment rates increased to 50 and 40 per cent respectively for the cohort of women born in 1974 (for further discussions of these education trends, see Stanfors 2003).

\section{Data Description}

Our dataset is based on the Swedish registration system and provides comprehensive information on fertility and other life course events as well as socio-economic background variables for almost all Swedish women born 1946 - 62. In particular, our data consist of 891,066 Swedish women born in Sweden during 1946-62. We do not consider immigrants, which reduces the number of individuals in the dataset by 27,761 women. We also drop one woman who is reported to have her first child in 1897, although she was born in 1960. This leaves the dataset with 863,304 women. The data include information on dates of various demographic events (child birth, marriage, divorce, death, emigration and immigration) and longitudinal observations on important economic variables such as income or public study benefits that occur prior to December 31, 1999.

Our analyses primarily rely on the variables pertaining to a woman's educational attainment, her month/year of birth, the month/year of birth of all her children, and the month/year of her first marriage. Basic summary statistics for these variables are reported in Table 2. While the subset of women that experienced a first or second birth does not change substantially across birth cohorts, the percentage of women that marry declines in younger cohorts. There have also been substantial increases in the age at first

leave if a next child arrives within a fixed period of time. In 1980, this period was set to 24 months while it was extended to 30 months in 1986. 
and second birth across cohorts, paralleling the increase in the mean age at first marriage. In addition, about 82 per cent of all women in our data set continued education after finishing compulsory (primary) school, and the most widespread levels of completed education are 1 or 2 years of secondary education followed by tertiary education.

\section{Results}

In this section we first discuss results of a woman's birth month on her age at first and second birth and the age of her first marriage. In addition, we report the probabilities of experiencing these events prior to age 37 or 45 and we provide an analysis of completed fertility and its relation to a woman's birth month. In order to investigate the mechanisms mediating the birth-month effects on the timing of fertility and marriage, we also provide an analysis of the effect of birth month on the level of completed education.

\subsection{Age at first birth}

The Swedish school enrolment implies that all women born in the same calendar year enter primary school in the same year - the year they become seven years old — and variations in birth month translate directly into differences the age at completing primary and potentially also secondary and tertiary education: within a birth cohort, women born in January are the oldest at graduation, exceeding the age of December-born women in the same birth cohort by eleven months, and across two birth cohorts, women born in December in the first cohort are eleven months younger at graduation than women born in January in the subsequent birth cohort.

Because our data are based on register data with a large number of women, simple plots of the mean age at first birth by birth month and cohort can reveal the influence of birth month and school enrolment on the timing of fertility. In Figure 3 we therefore depict the mean age at first birth for women by birth months for cohorts 1946-62. Across all cohorts in this Figure, the mean age at first birth increases from 23.8 years to 26.3 years, and this overall trend is consistent with the postponement of childbearing that we discussed in the "Recent trends in fertility and educational attainment in Sweden" section based on period data. The primary difference between the period and cohort pattern is the stabilization and subsequent decline in the mean age at first birth for the youngest birth cohorts (those born 1960-62). This stabilization and decline in Figure 3, however, is in part due to censoring of our data since many women in the youngest cohorts have not yet completed childbearing as of 1999 .

The most important aspect of Figure 3 is the trend in the mean age at first birth across birth months within each birth cohort, and between the two consecutive months December and January at the end of one and the beginning of the next calendar year. In particular, Figure 3 shows that the largest difference in the age at first birth between any two successive calendar months occurs between December of one and January of the next year. On average, women born in December experience their first birth 4.9 months earlier than 
women born one month later in January of the next year. Moreover, despite an increase of 2.5 years in the age at first birth across the cohorts 1946-62, there is a decline in the age at first birth within every birth cohort: on average, women born in January are 3.1 months older at the birth of their first child than women born in December of the same calendar year. Although the age at first birth declines relatively gradually over birth months within the same birth cohort, the largest average within-year difference of 3.7 months is found between those born in April and November. A possible explanation of this could be that women from higher social classes, who tend to have a higher age at birth, are more likely to give birth in spring (Smithers and Cooper 1984).

The above patterns are confirmed in more sophisticated analyses based on event-history models. In Figures 4.a-4.c we first present Kaplan Meier estimates of the "survival function" in the childless state for the cohorts 1946-1951, 1952-1957 and 1958-1962 by birth month. The graphs therefore show the proportion childless by the age of woman. For simplicity, we combine women born from January to June and those born from July to December. Consistent with our discussion above, the graphs show that those born in the first half of the year tend to have a later onset of first birth, relative to those born in the second half of the year. In addition, the analyses also indicate that this birth month effect is a pure tempo effect and the probability of entering motherhood prior to age 45 does not differ depending on the woman's month of birth (for more detailed analyses, see section "Overall probability of childbirth and marriage").

In Table 3 we report further results based on a piecewise constant hazard rate model that includes dummies for birth cohorts and interactions between the birth month and the age of a woman (the birth month coefficient is age-varying) and where individuals are right censored when they emigrate or die. In particular, we allow the effect of birth month to differ according to three age groups: below age 25, age 25-28 , and above age 28 . These age categories roughly reflect first-birth childbearing at relatively young ages, at the "prime" ages of first-birth fertility, and at relatively late ages of first-birth childbearing. Most importantly, Table 3 reveals that the effect of birth month on the first birth hazard differs systematically across these age groups. At relatively young ages of childbearing, women born in the first half of a calendar year tend to have lower first-births hazards as compared to women born in the second half of the year. During the prime and relatively late ages of first-birth childbearing, however, this pattern reverses: women born early in a calendar year have a higher first-birth hazards than women born late in a year. This shift in the pattern of relative hazards (relative with respect to the birth month) as ages increase implies a "catching up" of first birth fertility across birth months, and as a consequence, it implies that the birth month of a woman affects primarily the timing of fertility while leaving the overall probability of experiencing a first birth unaffected (see also Figures 4.a-4.c).

In summary, the analyses in Figure 3 reveal that an eleven months difference in the age at graduating between children born in December and the subsequent January results in a 4.9 months delay in the age at first birth. That is, $4.9 / 11=45 \%$ of the increase in the age at graduation from school is not caught up in early adulthood: $45 \%$ of the difference in the age at graduation is still reflected in an important 
demographic event, the first birth, that occurs on average 9 years after graduating from primary school and 5.5 years after graduating from highest education! $!^{6}$ This finding is further confirmed in our Kaplan-Meier estimates of the survival probability in the childless state and our estimates of event history models that reveal that a woman's month of birth has different effects at different stages in life: at young ages, being born in January decreases the risk of a first birth as compared to being born in December of the same calendar year, while this pattern reverses at older ages. As a result, a woman's month of birth affects only the timing of the first birth, while leaving the overall probability of having a first child virtually unaffected. This finding is particularly striking in light of the discussion that women have a desire about a specific age at first birth (conditional on human capital). If this were the case, one would expect that the duration between leaving school and having the first child provide sufficient opportunity to make up for the difference in the age at graduation. Nevertheless, empirically this seems not the case and a substantial difference in the age at first birth remains between women born in January and December within the same calendar year, or between women born in the two consecutive months December-January. Instead of age, the analyses therefore suggest that the time interval since school leaving age is an important determinant of the age at first birth, resulting in a long-term effect of differences in the age at graduation on the timing of demographic events later in life. Several of our subsequent analyses provide further support for this interpretation.

Seasonality differentials in the number of children born could potentially blur up our results. If women would aim at having their first births in the summer at a given age, then this could explain much of the seasonality differences we observe However, the highest number of first births are in Spring, and the lowest number in late Autumn, where 27\% more first births take place in March relative to November. These seasonality patterns can therefore not explain the clear cut difference in the age at first birth between January-December born women of the same year. One may even expect the opposite effect if we assume that women aim at spring births, January born may anticipate instead of postpone their childbearing. In addition, a preference for a specific birth season cannot explain the difference in the age at first birth between women born in the two consecutive months, December-January, since any sizable difference in the age at first birth between these women necessarily implies different birth seasons.

\footnotetext{
${ }^{6}$ Assuming uninterrupted educational careers, using educational duration data from the Swedish Level of Living Survey, women with primary school (pre- and post-reform), wait 7 years after leaving school before they have their first child. Individuals with short secondary school have a mean duration of 5.6 years, women with long secondary school wait 6 years, while those with short and long tertiary education (excluding the few individuals with Ph.D./licentiate degrees) have 4.7 to 4.2 years respectively. The mean duration from school graduation to first birth was 5.5 years.
} 


\subsection{Age at second birth}

Figure 3 also shows that the age at second birth has increased from 27.2 years to 29 years across the cohorts 1946-62, following a trend that is very similar to that in the age at first birth. Underlying this overall trend across cohorts, however, there is a systematic pattern across birth months that closely mirrors our findings for first births. First, our results indicate that variation in birth month and the associated variation in the age of entering and graduating from school prevails at the second birth, despite the fact that second births occur on average several years after the first birth. Within the same birth cohort, women who are born early tend to be older at the birth of their second child than those born late in the year. On average this age difference is 3 months between January-born and December-born women within the same cohort, and the difference tends to grow gradually with the difference between birth months. Moreover, there is again a substantial difference in the age at second birth among women born in the two consecutive months December-January, who are enrolled in school in two different calendar years, resulting in an age difference of 11 months at enrolment and graduation from primary school. In particular, women who are born in December are on average 4 months younger at the age of their second child than women who are born merely one month later in January. In both the within and across cohort comparisons, however, the different age at second birth is not associated with a different probability of having a second child (see Table 6).

Our earlier interpretation that duration since graduation—and not necessarily age itself —is an important factor in the timing of demographic events in early adulthood is clearly supported by analyses of second birth timing. For instance, Figure 5 depicts the duration (in months) between the first and the second birth, and it reveals, quite surprisingly, that there is no clear relationship between the age of school exit (indicated by a woman's birth month) and the duration between first and second child. The mean duration is 45.16 months, and the highest deviation is found between women born in April and November, where the former give birth to their second children on average at a 0.76 months shorter birth interval than the latter women. As a consequence, differences in the timing of first births across birth months - and in particular between December-January born women - are not compensated by a differential duration between the first and the second child. Thus, any delay in the age at first birth translates into an almost equal delay of the age at second birth.

This finding is surprising in light of the fact that many socio-economic approaches to the timing of fertility focus on the age at giving birth to the first, second, etc., child. If women had a strong desire about the age at second birth, however, one would expect that women tried to compensate for the age-differences in school graduation by adjusting their timing of the first birth and also their inter-birth spacing. Given our earlier findings about birth-month effects on first-birth timing, one would expect a systematic variation in the interbirth-spacing by women's month of birth. In particular, one would expect that January-born women in a birth cohort tend to have a shorter birth interval between the first and second child than December-born women in order to compensate for the older age at graduation and its effects on the timing of the first birth. The fact that this pattern is not revealed in our analyses provides a further indication that the duration since 
graduation from school and the duration since the previous birth are important determinants in the timing of second children, while age in itself may be secondary. As a result, delays in the age at graduation that are caused by school enrolment according to birth month lead to long-lasting effects on the timing of demographic events in early adulthood that occur several years after the graduation from school. For instance, the analyses in this section show that $4 / 11=36 \%$ of the age-difference in enrolling and graduating from primary school between women born in December and women born one month later in January stills persists when women give birth to their second children, which occurs on average between 10-12 years after graduation from primary school and more than 8 years after leaving school at the completion of education. $^{7}$

The above finding can be further supported with event history models, and Table 4 presents the results of a piecewise constant hazard rate model that includes birth-year dummies and interactions between birth month and a woman's age. Similar to our analyses of first births, birth month effects on the hazard of experiencing a second birth differ by a woman's age: at relatively young ages of second-birth childbearing, that is, below the age of 28 , women born in the first half of a calendar year experience a lower hazard rate than women born in the second half of the year. This relation reverses for women aged 28 to 32 , which is the age group with the highest risk of second childbirth, and this reversal becomes even stronger above age 32. After age 28 , therefore, women who are born early in a calendar year experience a higher hazard of giving birth to their second child than those born late in a year. This reversal also implies that women born early in a calendar year tend to catch up with their cohort-mates born late in the calendar year in terms of the overall probability of having a second child (see also "Completed fertility").

\subsection{Age at first marriage}

First marriage is a further important event in early adulthood that is potentially related to a woman's age at birth of the first child. Despite the fact that marriage in Sweden has become increasingly disconnected from childbearing in 1999, for instance, the share of out-of-wedlock births increased to 55\% (Statistics Sweden 2000) - most women in the cohorts born during 1942-62 eventually marry, albeit the fraction is declining in younger cohorts (82\% of women in the cohorts born 1946-1953 marry, and 68\% do in the cohorts born 1954-1962). For those being married, the timing of marriage has changed in close agreement with the timing of fertility. Figure 6 plots the age at first marriage by birth cohort and birth month, and it shows that the average age at first marriage has increased from 24.6 years to 27 years across the cohorts born 1942-$62 .^{8}$

\footnotetext{
${ }^{7}$ The duration from school leaving age until the birth of the second child averaged 8.6 years for women with uninterrupted educational careers.

${ }^{8}$ In the youngest cohorts there is likely to be substantial censoring because not all women who intend to marry have married (the youngest cohorts in our study have only reached the age 37 by the end of the
} 
The most striking fact of this trend towards delayed marriage — similar to our analyses of the timing of fertility - is that the postponement of marriage does not occur gradually across birth months. The biggest average increase of 3.5 months between women born in two consecutive birth months, coinciding with an 11 months difference in the age at graduation, occur again between those born in December and January; that is, $3.5 / 11=32 \%$ of the difference in the age at leaving school between women born in December and January the following year is still present in the age of first marriage. Within a birth cohort, women who are born later tend to marry at a younger age than women who are born early in a calendar year. For instance, women born in January are on average 2.1 months older when they marry for the first time than women born in December the same year. The relation between marriage and age at graduation/birth month is therefore almost identical to the corresponding relation between the age at first or second birth. In all cases, our analyses show long-lasting effects of birth month and age at graduation.

To support this finding further, we also estimate an event history model similar to that presented for first and second births. The results (Table 5) show that women born from January to June have a lower risk of marrying up to the age of 26, but have a higher risk of marrying at ages 26 and above. These higher intensities lead to a higher age at first marriage for women born in the first half of a calendar year as compared to women born in the second half, and this pattern also implies a higher overall probability of marrying prior to age 45 : about $76 \%$ of all women born in January married, while only $74 \%$ of the women born in December did so. This higher marriage probability for women born in January may be linked to self-esteem characteristics caused by their relative age in school class, as discussed in the "Overall probability of childbirth and marriage" section.

An alternative explanation that can potentially account for this relation between month of birth and age at first marriage is the summer marriage effect, that is, the fact that individuals are more likely to marry in summer time than other months of the year (about $57 \%$ of the marriages in Sweden take place during the four month period from May to August). Hence, if women from one birth cohort married in the middle of the summer of a given year, those born early in the year would marry at a higher age than those born later in the year. This effect could also partly explain the tendency that January-borns marry older. This effect, however, does not provide a good explanation for the difference in the age at marriage between women born in the two consecutive months December-January, unless the summer preference is also coupled with a wish to marry at the same time as ones school cohort.

\subsection{Overall probability of childbirth and marriage}

Although school enrolment policies and birth month mostly affect the timing of fertility and marriage, the analyses of the overall probability of childbirth and marriage deserves specific attention for at least two reasons. First, our primarily interpretation of birth-month influences on tempo effects in the previous

period studied), and the trend towards delayed marriage is likely to prevail in the youngest cohorts despite the fact that the data in Figure 6 show a leveling off. 
analyses is only appropriate if there are no strong birth month effects on the quantum of fertility or marriage within cohorts. Second, several of the studies reviewed in the survey section suggest that influence of birth month and school enrolment on the timing of fertility and marriage should also have second-order implications for the quantum of these events.

While we have already alluded to the absence of strong quantum effects associated with birth months, we investigate this issue in more detail in this section. In particular, we report in Table 6 the results of logistic regressions of the probability of having a first or second child, or having been married, by age 37 and 45 . The right-hand-side variables of these logistic regressions include dummy variables for birth year and birth month. The results in Table 6 confirm our earlier comments that there seem to be no relevant quantum effects associated with the month of birth within cohorts for fertility. The probability of having a first or second child prior to age of 37 or 45 does not change with birth month in any systematic way in Table 6 . However, there are small quantum effects with respect to marriage. Women born late in a year have a lower probability of marriage than women born early in the year, and this difference occurs at age 37 and age 45 .

One possible cause of the higher marriage risk for those born early in the year is that they have higher levels of self-confidence due to their older age in class and consequently a higher risk of attracting and marrying a partner. Breznitz and Teltsch (1989), for instance, find that first graders who are older in class are more socially successful and do better in subject tests than their classmates, and studies by Uphoff and Gilmore (1985) and Alton and Massey (1998) suggest that these relative class age effects remain throughout the school years and may increase educational attainment (Sharp 1995). The effect of being older in class can lead to higher self-confidence, which for example can lead to improved athletic achievement (Thompson et al. 1991) or higher wages (Plug 2001).

\subsection{Completed fertility}

In addition to our earlier analyses, the number of children born to women — or completed fertility—is a central aspect of demographic behavior in the context of our study. Its relation to birth months is interesting in its own right, and it is also relevant in connection with the above effects of birth months on the timing of fertility. In particular, several studies have shown that delays in the timing of the first child are negatively associated with the level of completed fertility (see the survey section). This finding suggests that the changes in the timing of fertility should affect completed fertility and that birth months early in the year should be related to slightly lower fertility than births months late in the year. However, Figure 7, which shows the completed fertility of women by birth cohort and birth month, does not confirm this expectation. While there are substantial — and presumably random—-fluctuations in completed fertility across birth months within each birth cohort, these fluctuations do not follow a specific pattern. In particular, the difference in the age at first birth between women born in December and the subsequent January is not associated with a systematic difference in completed fertility. This absence of a systematic pattern is confirmed using regression analyses. In Table 7 we report the regression results of fertility at age 45 (for cohorts born 1946-54) or age 37 (for cohorts born 1946-62) on birth-year and birth-month dummy 
variables. ${ }^{9}$ In contrast to the analyses of the timing of fertility or marriage, the birth month of a woman is not significantly related to the approximated completed number of children (measured at the age 45), and the hypothesis that all birth months dummies in Table 7 are equal to zero cannot be rejected. When studying fertility of all cohorts up to the age of 37 , some significant birth month effects are found. However, these effects are small and no systematic pattern is evident. In summary, therefore, the effect of the birth month and the resulting variation in the age at entering/graduating from primary school is concentrated on the timing of fertility and does not extend to completed fertility: neither the probability of having one or two children, nor the overall level of fertility differs systematically across women's month of birth.

\subsection{Educational attainment}

In our final analyses we investigate whether the overall educational attainment of women constitutes a mechanism that mediates the effect of birth month and the associated variation in the age at graduating from primary school on the timing of fertility and marriage.

The basic assumption of our analyses is that parents cannot fine-tune the birth of their children at the level of the birth month, and that the month of birth of a person is exogenously determined. Moreover, we assume that the month of birth does not affect school exit age through any other mechanism than the age at school entry as determined by the school enrolment laws. Because of the rigid Swedish school system up to the completion of primary school, this assumption is very plausible. For secondary and tertiary schooling, however, women (or their parents) make conscious decisions about continued education. These decisions can potentially include the consideration of birth month and its implications for the age at graduation and the timing of demographic events. In order to investigate this possibility we estimate logistic regressions of the probability that a woman completes 3 year secondary schooling or completes any form of tertiary education. The results of these logistic regressions in Table 8 reveal that the risk of completing any tertiary education is lower for those born from July to December, while the birth season's effect on completing a 3 year secondary education is much weaker. We attribute this difference to the relative class age effect: those who are born late in the year are among the youngest in their school class. This young age relative to classmates tends to reduce self-confidence and school performance, which in turn can reduce the risk of completing any tertiary education.

The observed moderate difference in educational level and duration of educational enrolment between those born early and late in a calendar year, however, does not explain why the birth month affects the timing of demographic events. In particular, even within every educational level the women born early in a calendar year are older at first or second birth or at marriage (Table 9). Moreover, the effect of birth month tends to

\footnotetext{
${ }^{9}$ Because the residual in these regressions is likely to be heteroscedastic, we use White's (1980) robust variance-covariance estimator to correctly estimate the standard errors of the coefficients. The coefficient itself are consistently estimated in OLS regressions despite this heteroscedasticity.
} 
be even stronger the higher is the level of secondary education: the difference between January-December borns is greater for women with long secondary schooling as compared to those with short secondary school, and longer for those with short secondary school relative to those with primary school. One potential reason for this effect is the fact that the duration between school leaving age and demographic events is shorter for those with an older school leaving age. Consequently there is less time left for an attenuation of the impact of the higher graduation age for those born early in the year on ages at experiencing demographic events in early adulthood.

Although the timing of demographic events for tertiary educated women still support the cut off date hypothesis-January borns are older than December borns- these differences are of a smaller magnitude than those for women with secondary education. According to our previous argument, we would rather expect an increase in the difference since tertiary educated are older when they graduate. However, the fact that tertiary schooling comprise a large variety of studies implies that the variance in graduation ages might be larger among tertiary as compared to secondary educated women and this may explain the smaller difference in the age at experiencing demographic events. In addition, taking into account the role of social interactions for the timing of demographic events may yield another argument for the lower age difference for demographic events of tertiary educated women: women with tertiary education, unlike those with shorter education, tend to study together with individuals from different age groups, and to a much lower extent only with individuals born in their own calendar year. Further, the increased educational attainment across birth cohorts can also not be used to explain the impact of the birth month on the risk of experiencing demographic events in early adulthood. Despite the fact that the educational attainment of a woman is associated with variation in the first birth risk ${ }^{10}$, the higher educational attainment of those born early in the year does not affect their fertility outcome and controlling for education does not alter the regression results in Tables 5 and 6 (analyses are not reported). Moreover, controlling for education does also not alter our results that an early birth month within a calendar year increases the probability of having married prior to age 45, and the results in Table 6 remain virtually unchanged when controlling for women's school level.

In summary, women who are born in the first months of the year have a slightly higher risk of completing a tertiary education relative to those born later in the year. The higher educational attainment of those born early in the year corresponds with the relative-class-age hypothesis; that those who are oldest in class turn out to be more self-confident and consequently perform better in school than the youngest in class. The longer schooling of those born early in the year does not mediate the birth month's effect on the timing of births and marriages - these timing effects remain also within the different schooling levels—so that the effect of the cut off date is valid. We also find a tendency of a stronger impact of the cut off date on the

\footnotetext{
${ }^{10} 86.4 \%$ of women with primary school as their highest education received a child, $88.4 \%$ of those with up to 2 years of secondary school, $83.9 \%$ of the individuals with 3 year secondary school and $84.8 \%$ of the tertiary educated received a child.
} 
timing of demographic events for women with longer education - this can be explained by the shorter duration from school leaving age until marriages and births take place for women with more educationwhich means that women who graduate at a later age have less time of "catching up" before becoming married or receiving children.

\subsection{Discussion}

Age constitutes one of the most central variables in demographic research and theories, and in recent years many theoretical and empirical studies have focused on explaining the changes in the timing of demographic events during early adulthood, and in particular, on the postponement of fertility and marriage. In this paper we utilize differences in women's age at graduation from school in Sweden, which is caused by a woman's month of birth and the Swedish school enrolment laws, to investigate how variation in the age at graduation from primary school at around age 16 affects the timing of demographic events in early adulthood for female cohorts born 1946-62. A striking finding of these analyses is that differences in the age at graduation from primary school, which are caused by the fact that children enroll in school in the calendar year they become seven years old, has substantial and long-lasting effects. For instance, $45 \%$ of the eleven months age difference in graduation between women born in December and the subsequent January is still present in the age at first birth. This occurs despite the fact that the age at first birth in cohorts 1946-62 is on average 8 to 10 years later than the age at graduation from primary school. Moreover, $36 \%$ of the age difference at graduation prevails when women experience their second birth, and $32 \%$ of the age difference still exists in the age at first marriage. Neither of these birth-month effects are associated with relevant quantum changes, and birth-month induced variation in the age at graduation primarily leads to tempo changes in fertility and marriage in early adulthood.

These patterns of tempo changes by birth month are surprising because the substantial time interval between graduation from primary school_occurring around age 16 - and the first marriage or first/second birth would seem to provide ample opportunity to compensate for the age difference at graduation from primary school if women had strong preferences about the age at which they experience these demographic events in early adulthood. Nevertheless, our study finds that a delayed age at leaving school within a birth cohort translates into a later timing of births and marriage, while leaving the probability of experiencing a first or second birth and the level of completed fertility virtually unaffected. In addition, our analyses do not find systematic differences in the birth interval between the first and second birth by mothers' month of birth. Differences in age of finishing primary education therefore have repercussion on timing of demographic events that follow several years after finishing primary education. Hence, our results suggest that women's desires or norms about the age at childbirth or marriage in Sweden seem to be of less importance as compared to the sequencing of those demographic events in relation to the time that has passed since finishing primary education.

In addition to stressing the importance of sequencing and duration since graduation, the above effects point to a potentially important social influence from individuals of the same school cohort, rather than 
individuals of the exact same age. In particular, the biggest changes in the timing of demographic events in early adulthood occur between school cohorts, that is, between women born in December and the subsequent January, despite the fact that women born during December-January differ on average only by one month in their age. Hence, women tend to synchronize the timing of demographic events-such as fertility and marriage - with women in their school cohorts rather than with women of similar age. In addition, the only relevant quantum effect associated with birth month in our study is that Swedish women born early in a calendar year tend to marry slightly more often, and have a slightly higher probability of attaining tertiary education. We attribute this result to the effect that these women tend to be the oldest members of their school cohort or class, which tends to improve self-confidence levels and school performance and this is likely to increase the probability of marriage and attaining higher education. Nevertheless, this effect of birth month on educational attainment does not constitute a mechanism that mediates the birth-month effects on the timing of fertility and marriage.

In summary, this paper provides the first analyses of how a woman's month of birth affects her age at first child, second child, marriage and completed fertility. The findings highlight the importance of the school cohort and the graduation age in the timing of demographic events, as observed by the rigid time interval from school leaving age until these events take place. This study also contributes to the literature on how the birth month can predict individual behavior, in particular since the effect of birth month on childbearing and family formation was not tested before. Moreover, the use of birth-month induced variation in the age at graduation constitutes a "natural experiment", and it therefore allows a study of education effects, and in particular the effect of the age at graduation from primary school, on demographic outcomes without the problems associated with unobserved heterogeneity and endogeneity that frequently hamper such analyses with standard survey data. 


\section{References}

Alton, A. and A. Massey (1998): "Date of Birth and Achievement in GCSE and GCE A-level." Educational Research 40 (1):105-109.

Andersson, G. (2000): “The Impact of Labor-Force Participation on Childbearing Behavior: Pro-cyclical Fertility in Sweden During the 1980s and the 1990s." European Journal of Population 16:293333.

Andersson, G. (2002): "Fertility Developments in Norway and Sweden Since the Early 1960s.” Demographic Research 6 (4):65-86.

Angrist, J. and Krueger, A. B. (1991): “Does Compulsory School Attendance affect Schooling and Earnings?" Quarterly Journal of Economics CVI, 4:979-1014.

Angrist, J.D. and Krueger, A.B. (1992): “The Effect of Age at School Entry on Educational Attainment: An Application of Instrumental Variables With Moments From Two Samples?” Journal of the American Statistical Association 87:328-336.

Barro, R. J. and J.-W. Lee (2000): “International Data on Educational Attainment: Updates and Implications." CID Working Paper 42 April. http://www2.cid.harvard.edu/ciddata/barrolee/Appendix.xls.

Becker, G. (1991): A Treatise on the Family. Harvard University Press.

Blossfeld, H.-P. and De Rose, A. (1992): "Educational Expansion and the Changes in Entry into Marriage and Motherhood. The Experience of Italian Women.”, Genus, 48:73-89.

Blossfeld, H.-P. and J. Huinink (1991): "Human Capital Investments or Norms of Role Transition? How Women's Schooling and Career Affect the Process of Family Formation.”, American Journal of Sociology, 97:143-168.

Bound, J. and D. A. Jaeger (1996): “On the Validity of Season of birth as an Instrument in Wage Equations: A Comment on Angrist and Krueger's “Does Compulsory School Attendance Affect Schooling and Earnings?"” NBER WP 5835.

Breznitz, Z. and T. Teltsch (1989): "The Effect of School Entrance Age on Academic Achievement and Social-Emotional Adjustment of Children.” Journal of Genetic Psychology 26:471-483.

Bumpass, L. L., R. R. Rindfuss, and R. B. Janosik (1978): “Age and Marital Status at First Birth and the Pace of Subsequent Fertility." Demography 15:75-86.

Council of Europe (2001): Recent Demographic Developments in Europe Council of Europe Press: Strasbourg. 
Corijn, M. (1996): Transition into Adulthood in Flanders. Results from the FFS. NIDI/CBGS Publications, Den Haag.

Costas, Meghir and M. Palme (2001): “The Effect of a Social Experiment in Education.”, Institute for Fiscal Studies Working Paper 01/11.

Doblhammer, G. and J. W. Vaupel (2001): "Life Span Depends on Month of Birth.”, Proceedings of the National Academy of Sciences 98 (5):2934-2939.

Goldin, C. and L. F. Katz (2002). “The Power of the Pill: Oral Contraceptives and Women's Career and Marriage.” Journal of Political Economy 110(4):730-770.

Gustafsson, S. (2001): “Optimal Age at Motherhood. Theoretical and Empirical Considerations on Postponement of Maternity in Europe.” Journal of Population Economics 14:225-247.

Hoem, B. (2000): "Entry into Motherhood in Sweden: The Influence of Economic Factors on the Rise and Fall in Fertility, 1986-1997." Demographic Research 2 (4).

Kohler, H.P; A. Skytthe and K. Christensen (2001): “The Age at First Birth and Completed Fertility Reconsidered: Findings from a Sample of Identical Twins.”, Max Planck Institute for Demographic Research Working Paper WP-2001-006.

Kohler, H.P., F.B Billari and J. A. Ortega (2002): “The Emergence of Lowest-Low Fertility in Europe During the 1990s." Population and Development Review 28 (4):641-680.

Lesthaeghe, R. and D. Meekers (1996): "Value Change and the Dimension of Familism in the European Community." European Journal of Population 2: 225-268.

Lesthaeghe, R. (1998): "On Theory Development. Application to the Study of Family Formation." Population and Development Review 24:1-14.

Marini, M. M. and P. J. Hodson (1981): "Effect of the Timing of Marriage and First Birth on the Spacing of Subsequent Births.” Demography 18(4):529-548.

Marini, M. M. (1984). “The order of Events in the Transition to Adulthood.”, Sociology of Education 57:63-84.

Morgan. P.S. and R. R. Rindfuss (1999): "Re-Examining the Link of Early Childbearing to Marriage and to Subsequent Fertility.” Demography 36 (1):59-76.

Neiss, M., D.C. Rowe and J.L. Rodgers (2002): "Does Education Mediate the Relationship Between IQ and Age of First Birth? A Behavioral Genetic Analysis.” Journal of Biosocial Science 34:259-275.

Nonaka, K., I. Nakamura, M. Shimura and T. Miura (1987): "Secondary sex ratio and the Month of a Mother's Birth - a Hypothesis of Sex-Ratio-Decreasing Factors.” Progress in Biometeorology 5:51-60. 
Oppenheimer, V. K. (1988): “A Theory of Marriage Timing.” American Journal of Sociology 94:563-591.

Plug, E. J. S. (2001): "Season of Birth, Schooling and Earnings.” Journal of Genetic Psychology, 22:641660.

Retherford, R.D. and Sewell, W.H. (1989): “How Intelligence Affects Fertility.” Intelligence 13:169-185.

Rosenzweig, M. R. and K. I. Wolpin (2000): "Natural "Natural Experiments" in Economics.” Journal of Economic Literature XXXVIII:827-874.

Riksförsakringsverket (2002): Föräldrapenning, Riksförsakringsverket: Vägledningar 2002 (1).

Schultz, T. P. (1993): “Returns to Women's Education.” Pp. 51-99 in E. M. King and M. A. Hill (eds.) Women's Education in Developing Countries: Barriers, Benefits, and Policies Baltimore: Johns Hopkins University Press.

Sham, P. C., E. O’Callaghan, N. Takei, G. K. Murray, E.H. Hare and T. M. Murray (1992): “Schizophrenia Following Prenatal Exposure to Influenza Epidemics Between 1930 and 1960." British Journal of Psychiatry 160:461-466.

Sharp, Caroline (1995): "What's age got to do with it? A study of patterns of school entry and the impact of season of birth on school attainment." Educational Research 37 (3):251-265.

Smithers, A.G. and H.J. Cooper (1984): “Social class and season of birth.” Journal of Social Psychology 124:79-84.

Stanfors, M. (2003): Education, labor force participation and changing fertility patterns. A study of women and socioeconomic change in twentieth century Sweden, Lund Studies in Economic History 22, Almqvist \&Wiksell International, Sweden.

Statistisk Tidsskrift (1962): Elevernas ålder höstterminen 1960 : Age Distribution of Pupils in Different Sections of the Educational System. Stockholm: Statistics Sweden.

Statistics Sweden (1998): Barnafödande och sysselättning. Upp-och nedgången i fruktsamheten 1985 1997. Stockholm: Statistics Sweden.

Statistics Sweden (2000): Befolkningsstatistik del 4 för 1999 , Stockholm: Statistics Sweden.

Statistics Sweden (2002): "Hur många barn får jag när jag blir stor? Barnafödande ur ett livsperspektiv.", Demografiska rapporter 2002, 5, Stockholm: Statistics Sweden.

Statistiska Meddelanden (1964): Elevernas Ålder Höstterminen 1963 : Age Distribution of Pupils. Stockholm: Statistics Sweden.

Statistiska Meddelanden (1968): Elevernas Ålder Höstterminen 1966 : Age Distribution of Pupils. Stockholm: Statistics Sweden. 
Statistiska Meddelanden (1970): Elevernas Ålder Höstterminen 1969 : Age Distribution of Pupils. Stockholm: Statistics Sweden.

Thompson, A. H., R. Barnsley and G. Stebelsky (1991): "Born to Play Ball: The Relative Age Effect and Major League Basketball.” Sociology of Sport Journal 8:146-151.

Trussel, J. and J. Menken (1978): "Early Childbearing and Subsequent Fertility.” Family Planning Perspectives 10 (4):209-218.

Uphoff, J.K., \& J. Gilmore (1985): "Pupil Age at School Entrance -How Many are Ready for Success?" Educational Leadership 63:86-90.

Van de Kaa, Dirk J. (1987): “Europe’s Second Demographic Transition.” Population Bulletin 42:389-432.

Westoff, C. F. and N. B Ryder (1977): The Contraceptive Revolution, Princeton: Princeton University Press.

White, H. (1980): "A Heteroskedasticity-Consistent Covariance Matrix Estimator and a Direct Test for Heteroskedasticity.” Econometrica 48: 817-830. 


\section{Tables}

Table 1. Highest Level of Education by Birth Cohort

\begin{tabular}{lccccc}
\hline $\begin{array}{l}\text { Birth } \\
\text { Cohort }\end{array}$ & $\begin{array}{l}\text { Primary } \\
\text { education }\end{array}$ & $\begin{array}{l}\text { Secondary } \\
\text { education }\end{array}$ & $\begin{array}{l}\text { Post- } \\
\text { secondary } \\
\text { education } \\
<3 \text { years }\end{array}$ & $\begin{array}{l}\text { Post- } \\
\text { secondary } \\
\text { education } \\
>3 \text { years }\end{array}$ & $\begin{array}{l}\text { Missing } \\
\text { values }\end{array}$ \\
1929 & $57 \%$ & $29 \%$ & $5 \%$ & $6 \%$ & $2 \%$ \\
1931 & $54 \%$ & $31 \%$ & $5 \%$ & $8 \%$ & $2 \%$ \\
1934 & $48 \%$ & $34 \%$ & $7 \%$ & $9 \%$ & $2 \%$ \\
1939 & $38 \%$ & $39 \%$ & $9 \%$ & $12 \%$ & $1 \%$ \\
1941 & $34 \%$ & $41 \%$ & $10 \%$ & $14 \%$ & $1 \%$ \\
1944 & $28 \%$ & $44 \%$ & $11 \%$ & $16 \%$ & $1 \%$ \\
1949 & $21 \%$ & $46 \%$ & $14 \%$ & $18 \%$ & $1 \%$ \\
1951 & $18 \%$ & $47 \%$ & $15 \%$ & $18 \%$ & $1 \%$ \\
1954 & $18 \%$ & $46 \%$ & $17 \%$ & $18 \%$ & $1 \%$ \\
1959 & $14 \%$ & $51 \%$ & $18 \%$ & $16 \%$ & $1 \%$ \\
1961 & $12 \%$ & $53 \%$ & $18 \%$ & $16 \%$ & $1 \%$ \\
1964 & $11 \%$ & $54 \%$ & $17 \%$ & $16 \%$ & $1 \%$ \\
1969 & $10 \%$ & $53 \%$ & $18 \%$ & $19 \%$ & $1 \%$ \\
1971 & $9 \%$ & $51 \%$ & $17 \%$ & $22 \%$ & $1 \%$ \\
1974 & $9 \%$ & $49 \%$ & $15 \%$ & $26 \%$ & $2 \%$ \\
\hline
\end{tabular}

Source: Statistics Sweden (Swedish Register of Education) 
Table 2. Descriptive Statistics

Sample Size

Average Number of Children (Standard Deviation)
863,304

$1.95(1.19)$

Percentage who before 31.Dec. 1999...

Birth Cohorts

$\begin{array}{rrrr}\text {...had a First Child } & 86.83 \% & 84.94 \% & 82.93 \% \\ \ldots \text { had a Second Child } & 71.16 \% & 70.80 \% & 69.64 \% \\ \ldots \text { had a First Marriage } & 83.61 \% & 75.06 \% & 64.16 \% \\ \text {...Emigrated } & 2.06 \% & 1.89 \% & 2.37 \% \\ \ldots \text { Died* } & 3.00 \% & 1.70 \% & 1.12 \%\end{array}$

Highest Completed Educational Level

Primary School (Pre-Reform)***

Primary School (Post-reform)

Secondary School, up to 2 Years

(Mostly Vocational Study Tracks)

Secondary School, 3 Years or more

(Academically oriented Study Tracks)

Tertiary education, up to 2 years

Tertiary education, above 3 years

Tertiary education, $\mathrm{PhD} /$ Licentiate degree

Unspecified Education
Number of Approximate Years of

\begin{tabular}{rr} 
Individuals & Schooling** \\
\hline $4.50 \%$ & 8
\end{tabular}

$13.55 \%$

$38.59 \%$

$9.20 \%$

$17.80 \%$

15

$14.10 \%$

17

$0.37 \%$

21

Age at Demographic Events

\begin{tabular}{rrrr} 
& \multicolumn{3}{c}{ Birth Cohorts } \\
& $1946-1951$ & $1952-1957$ & $1958-1962$ \\
\cline { 2 - 4 } First Child & 24.14 & 25.20 & 26.22 \\
Second Child & 27.55 & 28.48 & 28.89 \\
First Marriage & 25.18 & 26.88 & 27.14
\end{tabular}

*Of the individuals who died, 92 had first emigrated.

**Years of schooling estimated by the Swedish Level of Living Survey for 1945-1955 cohorts (Costas and Palme 2001)

*** Between 1949 and 1962, compulsory Primary school was extended from 7 or 8 years to 9 years in Sweden (see Costas and Palme 2001 for details). Although the reform was introduced gradually, this was not done in any way that affected the cut-off month and the age-pattern of school enrolment. We therefore do not distinguish between pre-reform and post-reform primary school in our analysis. 
TABLE 3. RISK OF HAVING A FIRST CHILD (ALL WOMEN). PIECEWISE-CONSTANT HAZARD RATE MODEL (PROPORTIONAL HAZARD RATES)

\begin{tabular}{lrr}
\hline Baseline Hazard & $\begin{array}{r}\text { Up to 25 years } \\
25-28 \text { years }\end{array}$ & $0.022 * * *$ \\
& $0.139 * * *$ \\
28 years and above & $0.073 * * *$ \\
Born January-June: & Up to 25 years & $0.960 * * *$ \\
Age-Specific Effect & $25-28$ years & $1.012 * *$ \\
& 28 years and above & $1.031 * * *$ \\
Women's Birth Year & 1946 & 1 \\
& 1947 & 1.000 \\
1948 & 1.000 \\
1949 & 0.992 \\
1950 & $0.977 * * *$ \\
1951 & $0.960 * * *$ \\
1952 & $0.949 * * *$ \\
1953 & $0.942 * * *$ \\
1954 & $0.920 * * *$ \\
1955 & $0.917 * * *$ \\
1956 & $0.905 * * *$ \\
1957 & $0.904 * * *$ \\
1958 & $0.901 * * *$ \\
1959 & $0.886 * * *$ \\
1960 & $0.889 * * *$ \\
1961 & $0.876 * * *$ \\
1962 & $0.882 * * *$ \\
\hline Significant at 5\% Level, * Significant at $10 \%$ Level &
\end{tabular}


TABLE 4. RISK OF HAVING A SECOND CHILD (ALL WOMEN WITH ONE CHILD). PIECEWISE-CONSTANT HAZARD RATE MODEL (PROPORTIONAL HAZARD RATES)

Baseline Hazard

January-June:

Age-Specific Effect

Women's Birth Year

$\begin{aligned} \text { Up to 28 years } & 0.015 * * * \\ \text { 28-32 years } & 0.122 * * * \\ \text { 32 years and above } & 0.056 * * * \\ \text { Up to 28 years } & 0.958 * * * \\ 28-32 \text { years } & 1.009 * * * \\ \text { 32 years and above } & 1.024 *\end{aligned}$

$1946 \quad 1$

$1947 \quad 1.000$

$1948 \quad 1.010$

$19491.022 * * *$

$19501.027 * * *$

$1951 \quad 1.026 * * *$

$19521.032 * * *$

$19531.056 * * *$

$19541.063 * * *$

$19551.074 * * *$

$1956 \quad 1.085 * * *$

$1957 \quad 1.103 * * *$

$1958 \quad 1.106 * * *$

$19591.119 * * *$

$1960 \quad 1.147 * * *$

$1961 \quad 1.149 * * *$

$19621.164 * * *$

$* * *=$ Significant at $1 \%$ Level, $* *=$ Significant at $5 \%$ Level, $*=$ Significant at $10 \%$ Level 
TABLE 5. RISK OF FIRST MARRIAGE (ALL WOMEN). PIECEWISE-CONSTANT HAZARD RATE MODEL (PROPORTIONAL HAZARD RATES)

\begin{tabular}{lrc}
\hline Baseline Hazard & Up to 26 years & $0.023 * * *$ \\
& 26 years and above & $0.069 * * *$ \\
Born January-June: & Up to 26 years & $0.991 * * *$ \\
Age-Specific Effect & 26 years and above & $1.054 * * *$ \\
Women's Birth Year & 1946 & 1 \\
& 1947 & $0.969 * * *$ \\
& 1948 & $0.930 * * *$ \\
& 1949 & $0.886 * * *$ \\
& 1950 & $0.842 * * *$ \\
& 1951 & $0.812 * * *$ \\
& 1952 & $0.784 * * *$ \\
& 1953 & $0.770 * * *$ \\
& 1954 & $0.742 * * *$ \\
& 1955 & $0.720 * * *$ \\
& 1956 & $0.704 * * *$ \\
& 1957 & $0.691 * * *$ \\
& 1958 & $0.667 * * *$ \\
& 1959 & $0.655 * * *$ \\
& 1960 & $0.635 * * *$ \\
& 1961 & $0.622 * * *$ \\
& 1962 & $0.598 * * *$ \\
\hline Lignificant at $1 \%$ Level $* *$ Significant at $5 \%$ Level $*=$ Significant at $10 \%$ Level
\end{tabular}

***=Significant at $1 \%$ Level, $* *=$ Significant at $5 \%$ Level, $*=$ Significant at $10 \%$ Level 
TABLE 6. WOMEN'S RISK OF FIRST BIRTH, SECOND BIRTH AND MARRIAGE. LOGISTIC REGRESSION RESULTS (ODDS RATIO).

\begin{tabular}{|c|c|c|c|c|c|c|c|}
\hline & & First Child F & isk & $\begin{array}{l}\text { Second Chil } \\
\text { (Given that } \\
\text { Child) }\end{array}$ & $\begin{array}{l}\text { d Risk } \\
\text { one has a }\end{array}$ & Marriage $\mathrm{R}$ & isk \\
\hline & & $\begin{array}{l}\text { Until Age } \\
37\end{array}$ & $\begin{array}{l}\text { Until age } \\
45\end{array}$ & $\begin{array}{l}\text { Until Age } \\
37\end{array}$ & Until age 45 & $\begin{array}{l}\text { Until Age } \\
37\end{array}$ & $\begin{array}{l}\text { Until age } \\
45\end{array}$ \\
\hline Birth & January & 0.988 & 1.016 & $0.959 * * *$ & 0.995 & 0.995 & 0.998 \\
\hline Month & February & $0.974 *$ & 1.008 & $0.967 * * *$ & 0.998 & 1.010 & 1.015 \\
\hline & March & $0.971 * *$ & 0.996 & $0.972 * * *$ & 0.988 & 1.000 & 1.014 \\
\hline & April & $0.976 *$ & 1.016 & 0.991 & 1.001 & 1.004 & $1.030 *$ \\
\hline & May & 0.987 & 1.008 & 0.993 & $1.033 *$ & 0.993 & 1.026 \\
\hline & June & 1 & 1 & 1 & 1 & 1 & 1 \\
\hline & July & 0.979 & 0.981 & 1.003 & $1.039 *$ & $0.977 * *$ & 0.972 \\
\hline & August & 0.977 & 0.991 & 0.978 & 0.978 & $0.972 * *$ & 0.989 \\
\hline & September & $0.975 *$ & 0.993 & 0.995 & 0.995 & $0.954 * * *$ & $0.955 * *$ \\
\hline & October & 0.972 & 0.979 & 0.986 & 0.997 & $0.951 * * *$ & $0.964 * *$ \\
\hline & November & 0.984 & 0.994 & 0.979 & 0.994 & $0.944 * * *$ & $0.947 * * *$ \\
\hline & December & 0.976 & 0.992 & $0.969 * *$ & 0.976 & $0.924 * * *$ & $0.920 * * *$ \\
\hline Birth & 1946 & 1 & 1 & 1 & 1 & 1 & 1 \\
\hline Year & 1947 & 0.991 & 1.000 & 0.979 & 0.998 & $0.904 * * *$ & $0.934 * * *$ \\
\hline & 1948 & $1.045 * * *$ & $1.064 * * *$ & 0.989 & 1.016 & $0.847 * * *$ & $0.905 * * *$ \\
\hline & 1949 & 1.006 & 1.032 & 0.999 & $1.035 * *$ & $0.739 * * *$ & $0.809 * * *$ \\
\hline & 1950 & $0.943 * * *$ & 0.987 & 0.977 & $1.035 * *$ & $0.654 * * *$ & $0.724 * * *$ \\
\hline & 1951 & $0.900 * * *$ & $0.945 * * *$ & $0.960 * * *$ & $1.035 * *$ & $0.592 * * *$ & $0.671 * * *$ \\
\hline & 1952 & $0.866 * * *$ & $0.912 * * *$ & $0.965 * *$ & $1.038 * *$ & $0.551 * * *$ & $0.619 * * *$ \\
\hline & 1953 & $0.846 * * *$ & $0.898 * * *$ & 0.999 & $1.093 * * *$ & $0.650 * * *$ & $0.587 * * *$ \\
\hline & 1954 & $0.796 * * *$ & $0.849 * * *$ & 1.001 & $1.112 * * *$ & $0.590 * * *$ & $0.536 * * *$ \\
\hline & 1955 & $0.793 * * *$ & & 1.020 & & $0.544 * * *$ & \\
\hline & 1956 & $0.773 * * *$ & & $1.030 *$ & & $0.507 * * *$ & \\
\hline & 1957 & $0.776 * * *$ & & $1.065 * * *$ & & $0.473 * * *$ & \\
\hline & 1958 & $0.775 * * *$ & & $1.071 * * *$ & & $0.427 * * *$ & \\
\hline & 1959 & $0.742 * * *$ & & $1.094 * * *$ & & $0.398 * * *$ & \\
\hline & 1960 & $0.738 * * *$ & & $1.152 * * *$ & & $0.368 * * *$ & \\
\hline & 1961 & $0.708 * * *$ & & $1.155 * * *$ & & $0.342 * * *$ & \\
\hline & 1962 & $0.710 * * *$ & & $1.196 * * *$ & & $0.312 * * *$ & \\
\hline & $\mathrm{N}$ & 863304 & 477862 & 734743 & 412706 & 863304 & 477862 \\
\hline
\end{tabular}


TABLE 7. ANALYSIS OF THE ACCUMULATED NUMBER OF CHILDREN, WOMEN 37 AND 45 YEARS

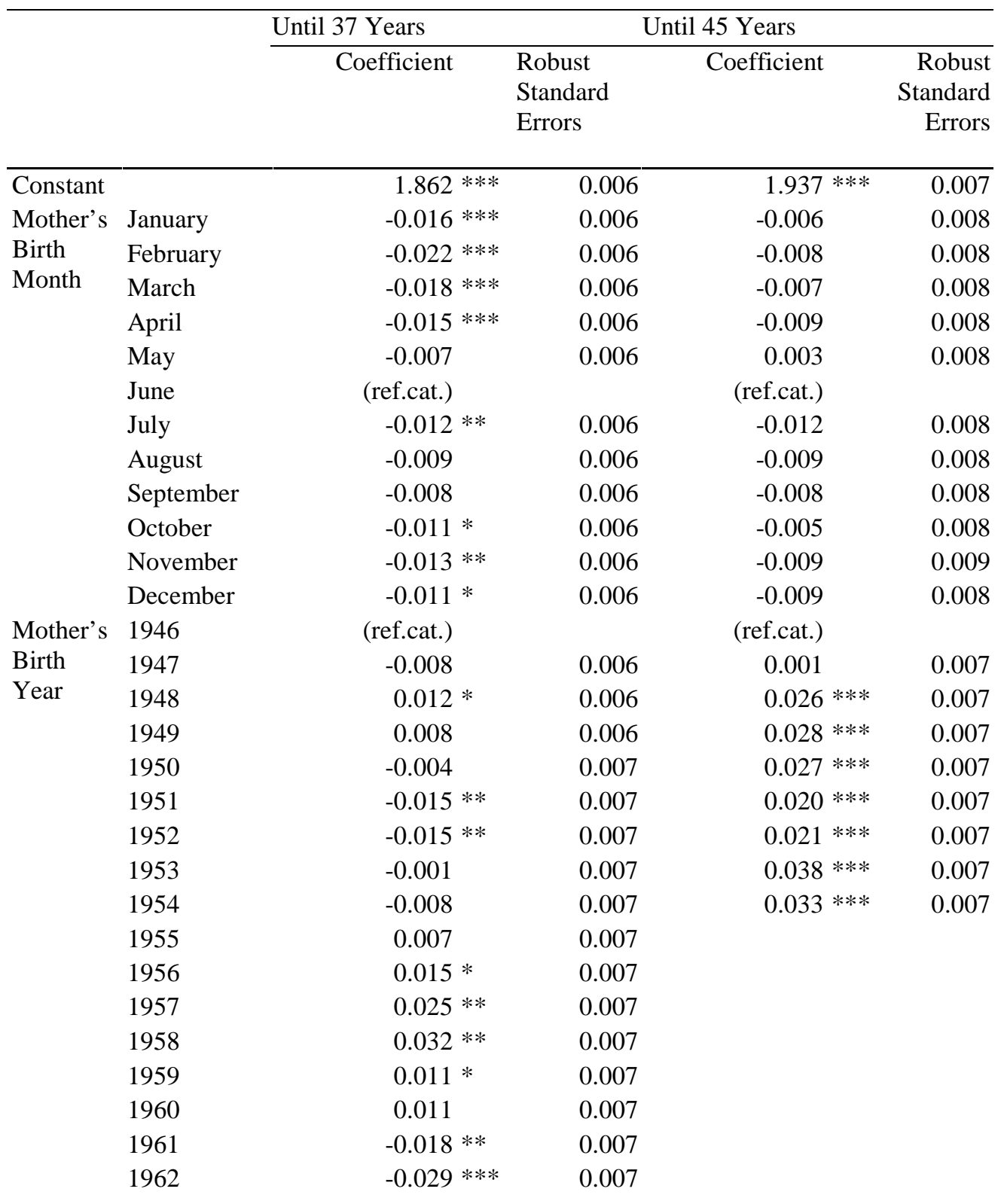


TABLE 8. WOMEN'S RISK OF EDUCATIONAL ATTAINMENT (ALL WOMEN). LOGISTIC REGRESSION RESULTS (ODDS RATIO).

\begin{tabular}{|c|c|c|c|}
\hline & & $\begin{array}{l}3 \text { Year Secondary } \\
\text { School }\end{array}$ & $\begin{array}{l}\text { Any Tertiary } \\
\text { Education }\end{array}$ \\
\hline \multirow{12}{*}{$\begin{array}{l}\text { Mother's } \\
\text { Birth } \\
\text { Month }\end{array}$} & January & 1.019 & $1.020 *$ \\
\hline & February & 0.994 & $1.053 * * *$ \\
\hline & March & 0.999 & $1.046 * * *$ \\
\hline & April & 1.000 & $1.057 * * *$ \\
\hline & May & 0.996 & $1.043 * * *$ \\
\hline & June & 1 & 1 \\
\hline & July & 0.974 & $0.978 * *$ \\
\hline & August & $0.965 *$ & $0.944 * * *$ \\
\hline & September & 0.981 & $0.969 * * *$ \\
\hline & October & 0.974 & $0.960 * * *$ \\
\hline & November & 0.983 & $0.953 * * *$ \\
\hline & December & 0.980 & $0.953 * * *$ \\
\hline Mother's & 1946 & 1 & 1 \\
\hline \multirow[t]{16}{*}{ Birth Year } & 1947 & $1.131 * * *$ & $1.084 * * *$ \\
\hline & 1948 & $1.198 * * *$ & $1.148 * * *$ \\
\hline & 1949 & $1.244 * * *$ & $1.255 * * *$ \\
\hline & 1950 & $1.324 * * *$ & $1.306 * * *$ \\
\hline & 1951 & $1.395 * * *$ & $1.320 * * *$ \\
\hline & 1952 & $1.418 * * *$ & $1.359 * * *$ \\
\hline & 1953 & $1.297 * * *$ & $1.352 * * *$ \\
\hline & 1954 & $1.351 * * *$ & $1.361 * * *$ \\
\hline & 1955 & $1.251 * * *$ & $1.387 * * *$ \\
\hline & 1956 & $1.250 * * *$ & $1.344 * * *$ \\
\hline & 1957 & $1.241 * * *$ & $1.348 * * *$ \\
\hline & 1958 & $1.287 * * *$ & $1.326 * * *$ \\
\hline & 1959 & $1.399 * * *$ & $1.271 * * *$ \\
\hline & 1960 & $1.434 * * *$ & $1.253 * * *$ \\
\hline & 1961 & $1.530 * * *$ & $1.253 * * *$ \\
\hline & 1962 & $1.718 * * *$ & $1.209 * * *$ \\
\hline
\end{tabular}


TABLE 9. AGE DIFFERENCE (IN MONTHS) BETWEEN INDIVIDUALS BORN IN JANUARY AND DECEMBER IN THE SAME YEAR

\begin{tabular}{lrrrr}
\hline Highest Completed Education & First Child $\begin{array}{l}\text { Second } \\
\text { Child }\end{array}$ & $\begin{array}{l}\text { First } \\
\text { Marriage }\end{array}$ & \multicolumn{1}{l}{$\begin{array}{l}\text { No. of } \\
\text { Individuals }\end{array}$} \\
\hline Primary School, 8-9 Years & 1.27 & 1.74 & 1.78 & 155822 \\
Secondary School, > 2 Years & 2.61 & 2.67 & 1.33 & 333133 \\
Secondary School, 3 Years & 5.91 & 4.65 & 3.14 & 79383 \\
Tertiary Education, Any Length & 1.76 & 1.65 & 1.42 & 278465 \\
\hline
\end{tabular}




\section{Figures}

Figure 1. Total Fertility Rate (TFR) and Mean Age at Birth of First Child

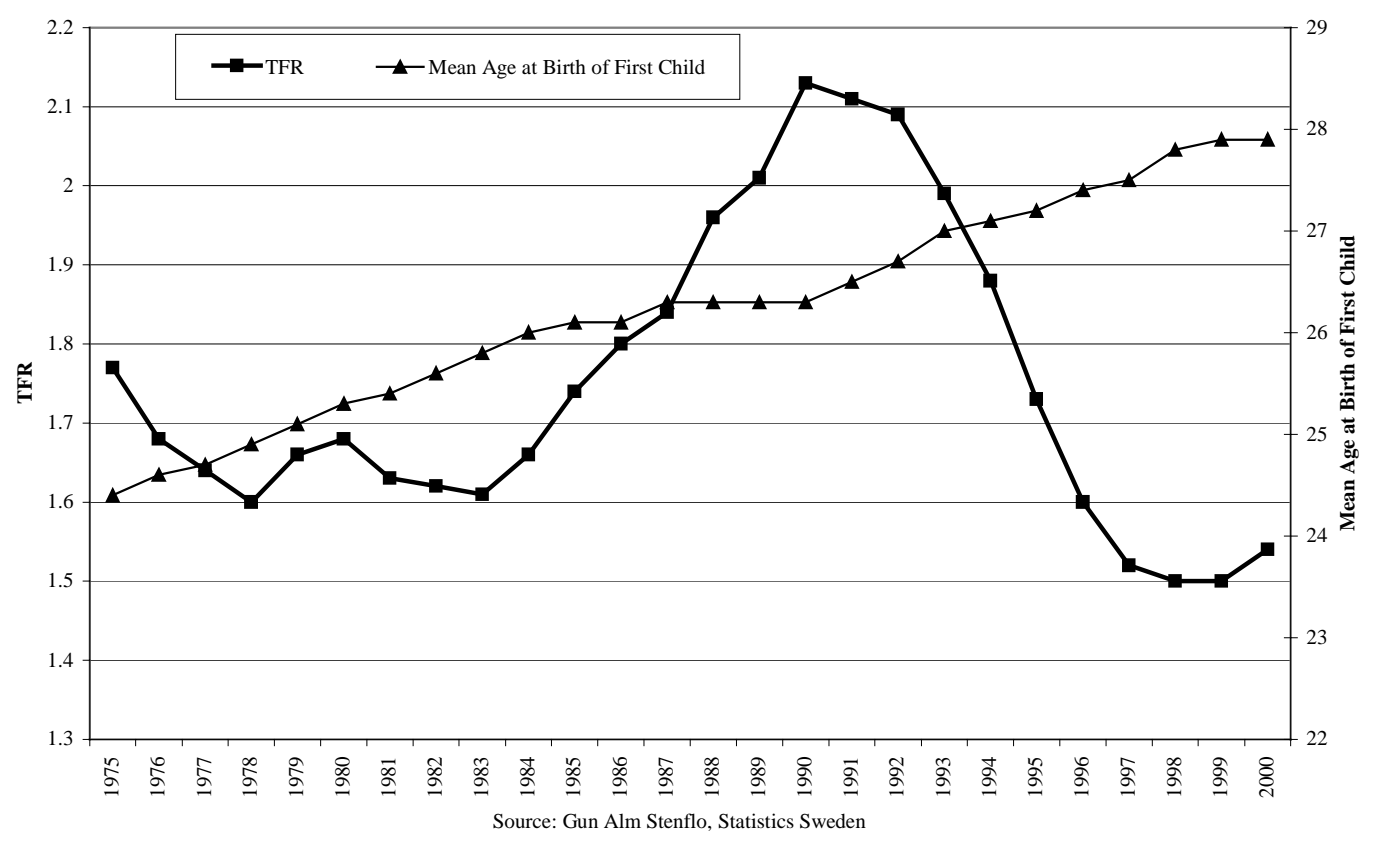


Figure 2. Years of Education for Women above 25 Years and Mean Age at Birth of First Child

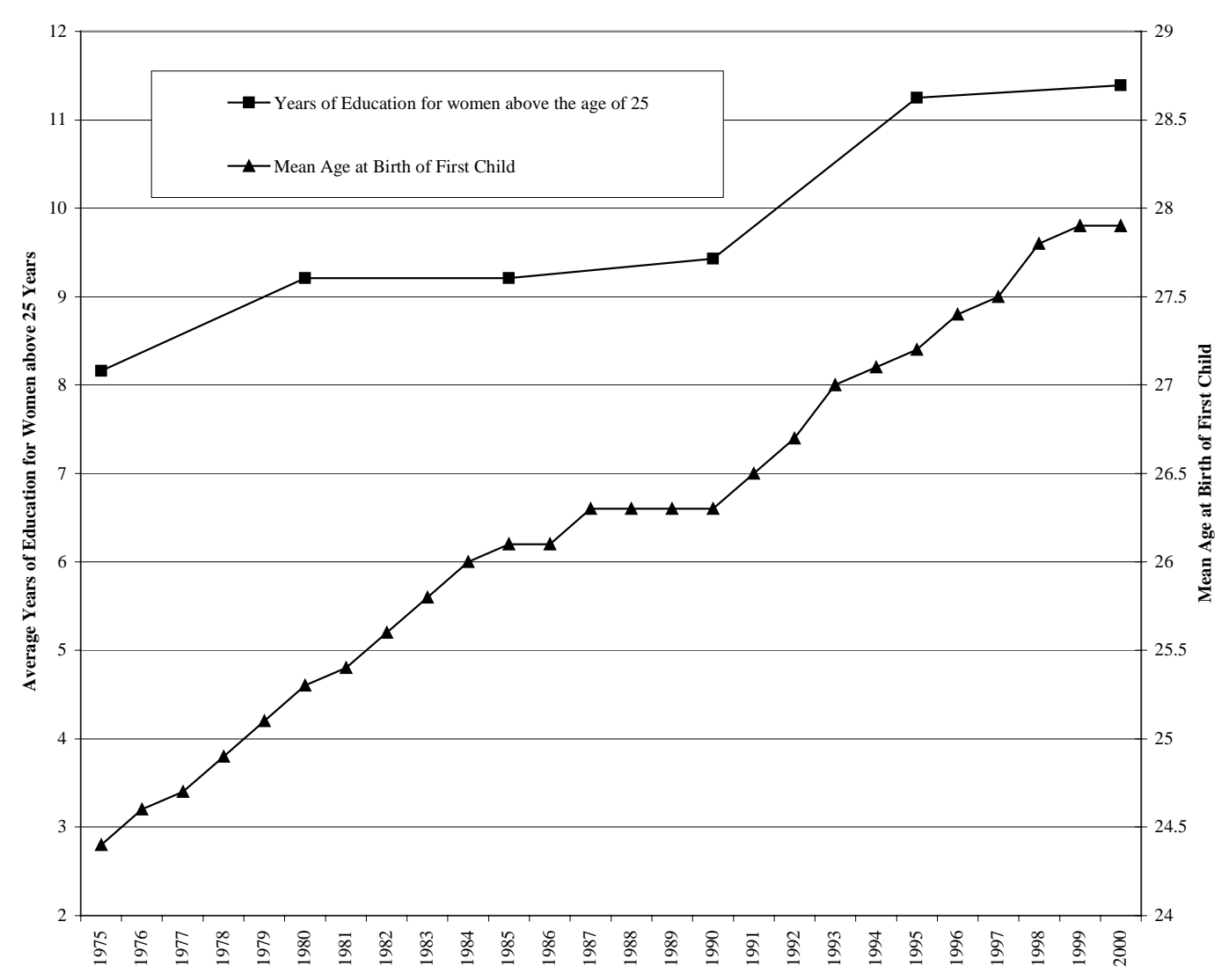

Source: Statistics Sweden, Barro and Lee: International Data on Educational Attainment 
Figure 3. Age at First and Second Childbirth

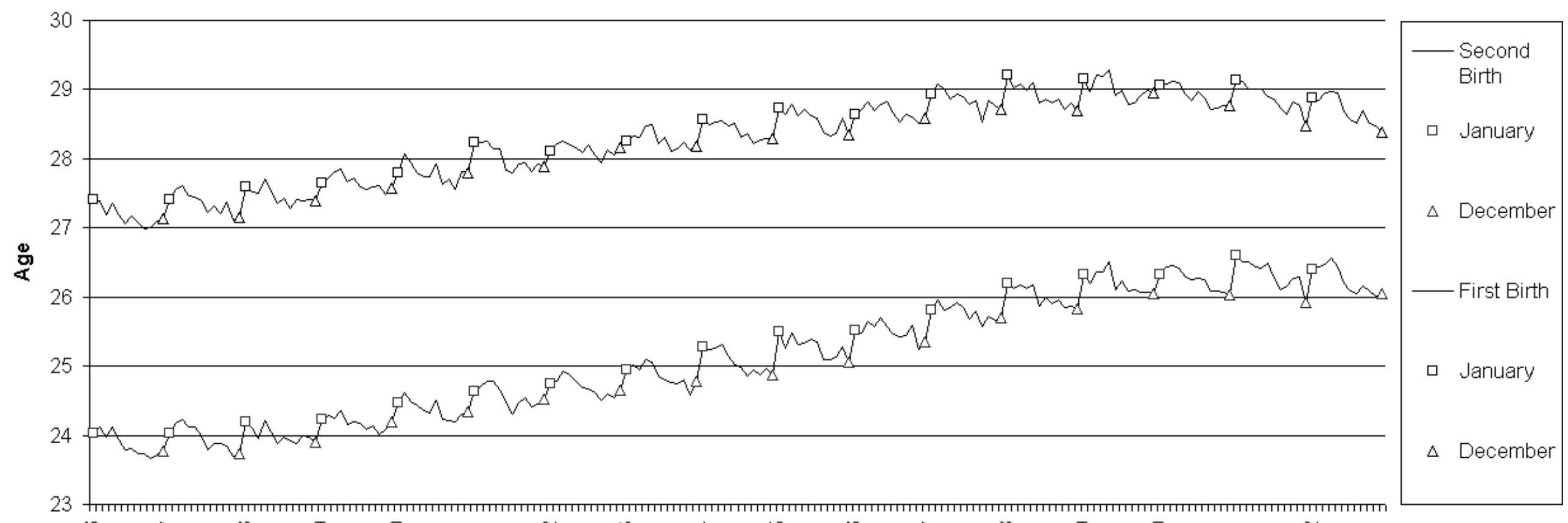

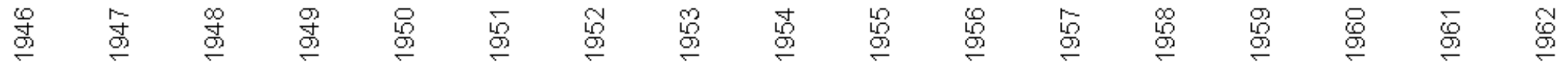

Birth Month and Year 
FIGURE 4.A FIRST BIRTH. KAPLAN-MEIER ESTIMATES, 1946-1951 COHORTS

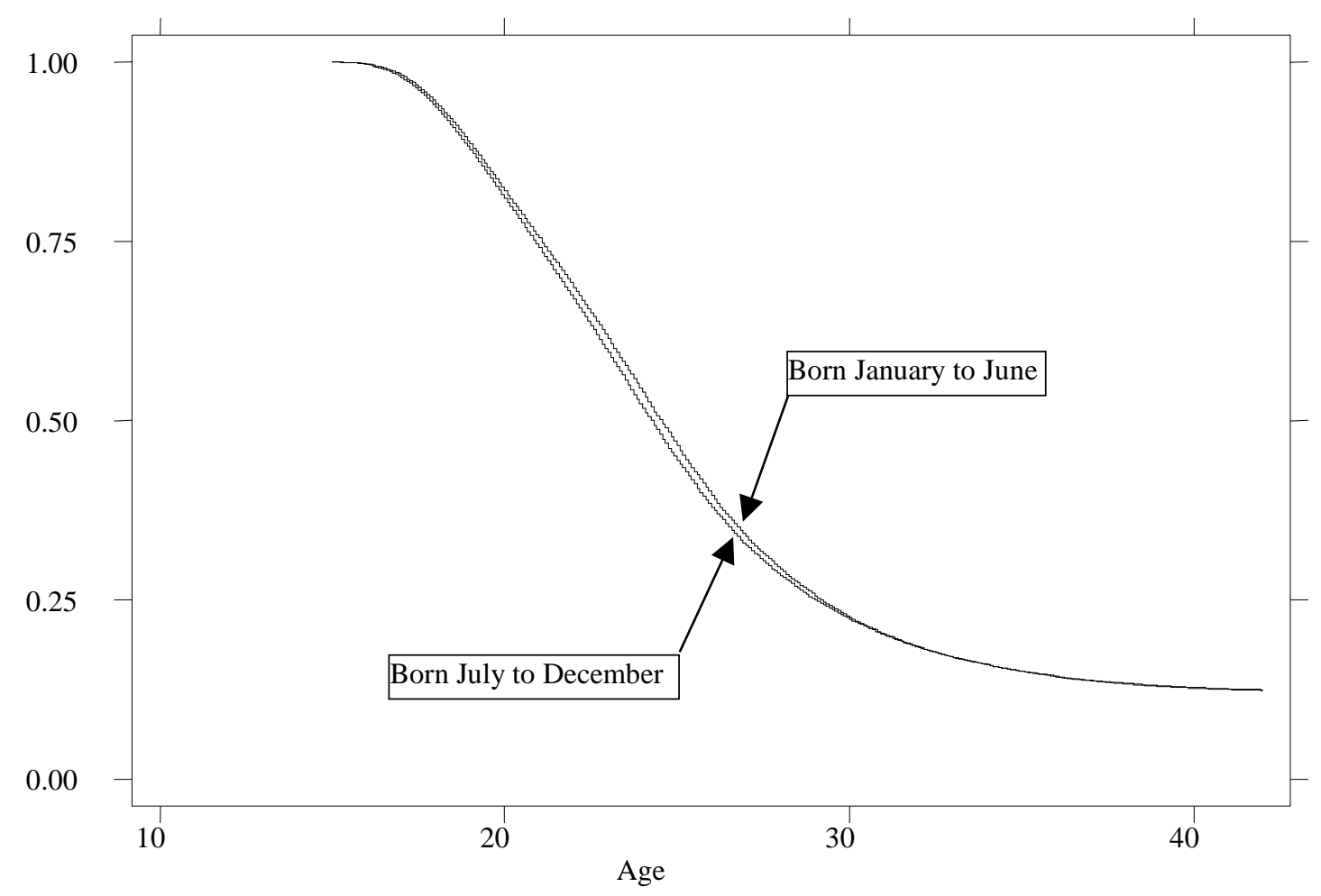


FIGURE 4.B. FIRST BIRTH. KAPLAN-MEIER ESTIMATES, 1952-1957 COHORTS

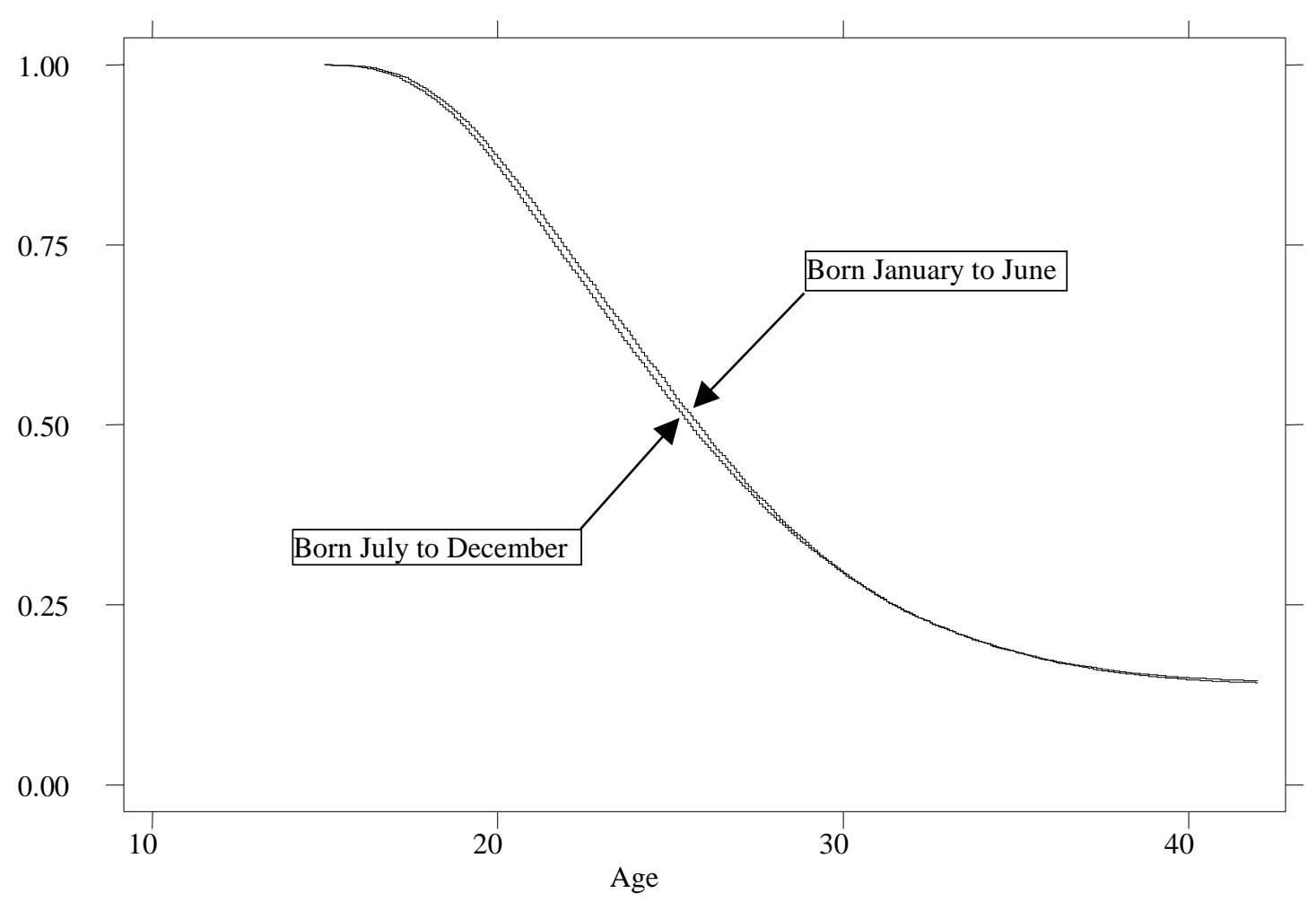


FIGURE 4.C. FIRST BIRTH. KAPLAN-MEIER ESTIMATES, 1958-1962 COHORTS

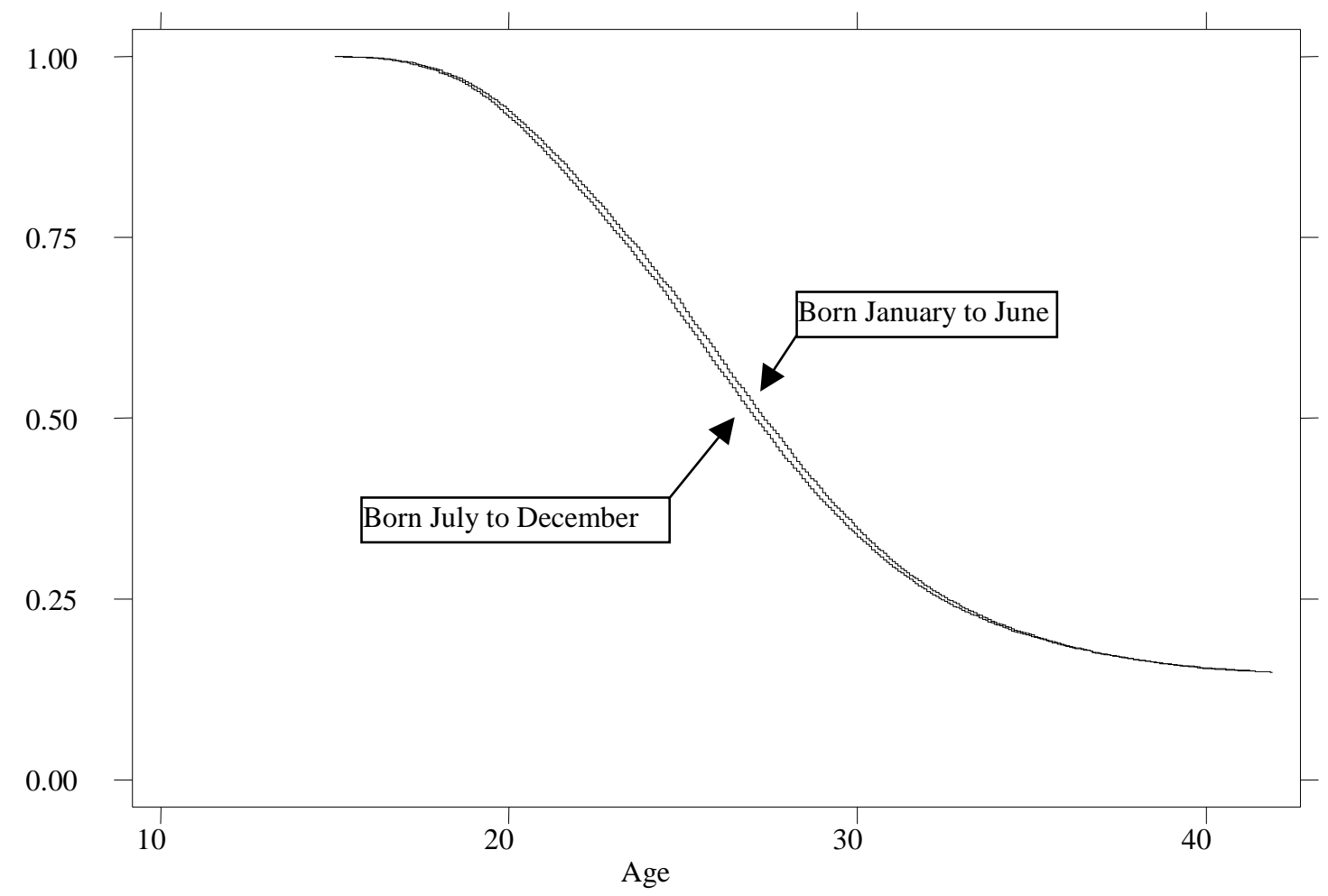


Figure 5. Duration from first to second birth

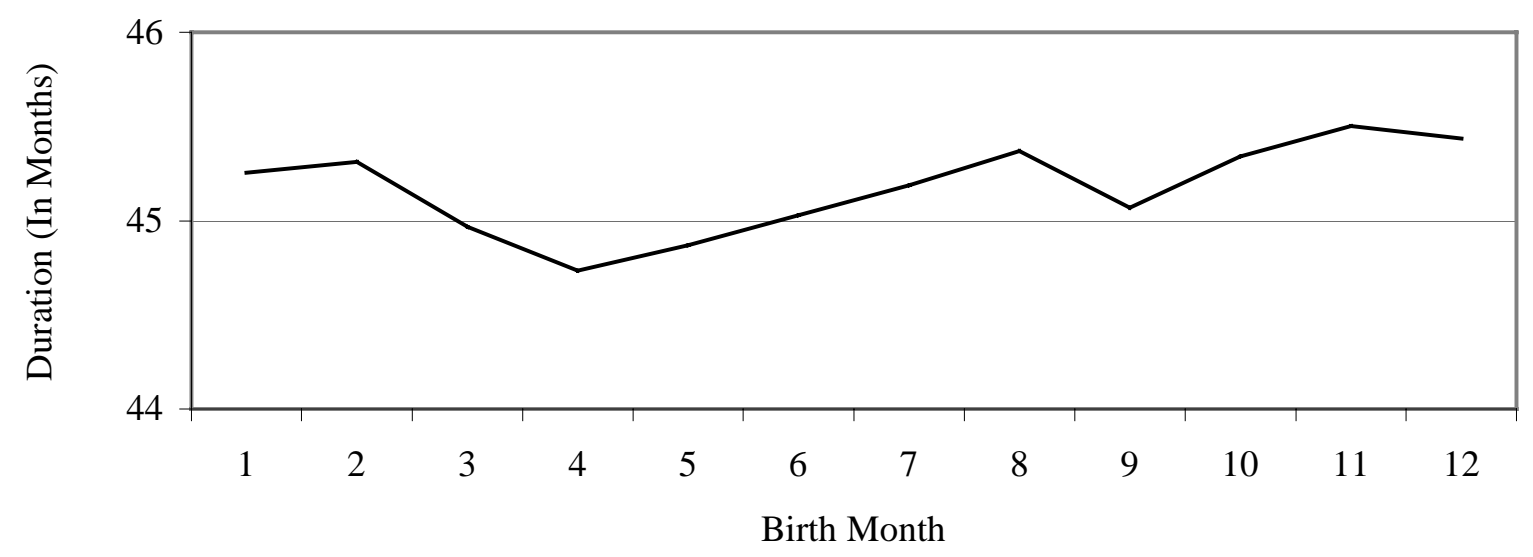


Figure 6. Age at First Marriage

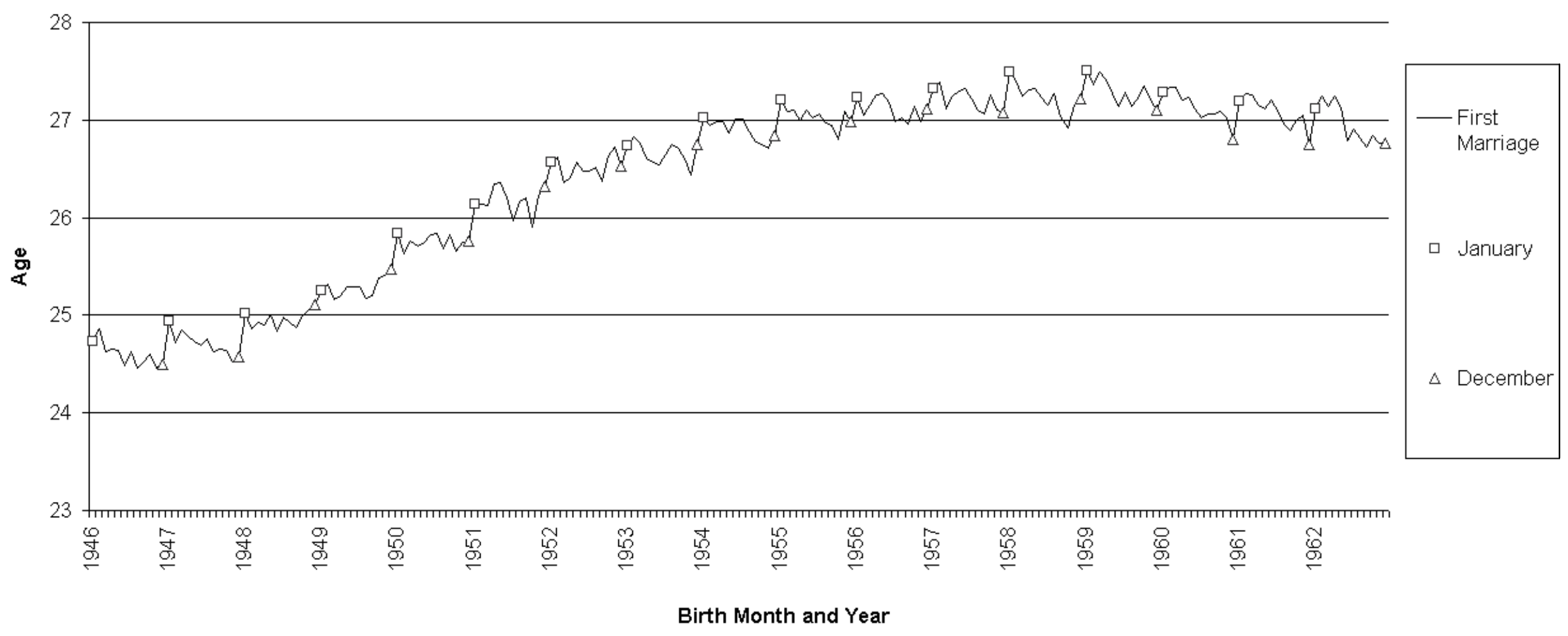


Figure 7. Completed Fertility

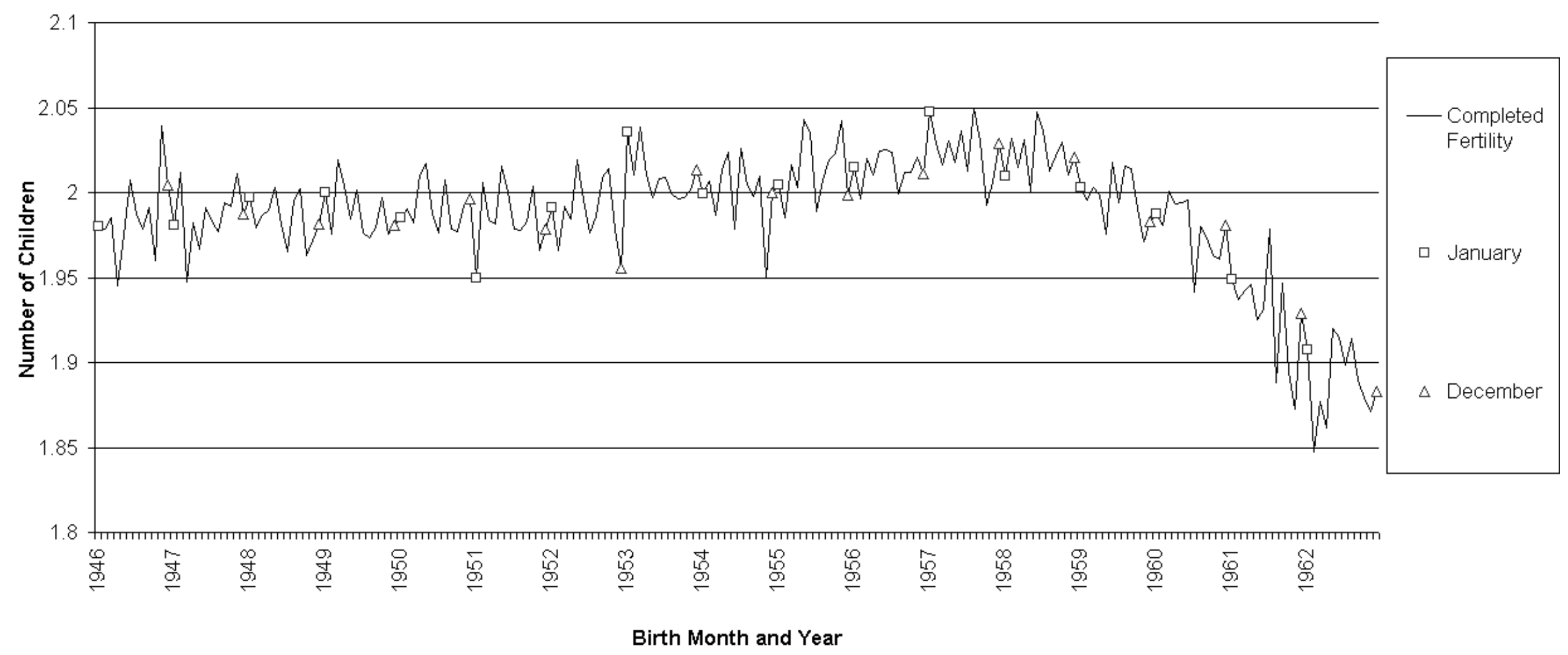

